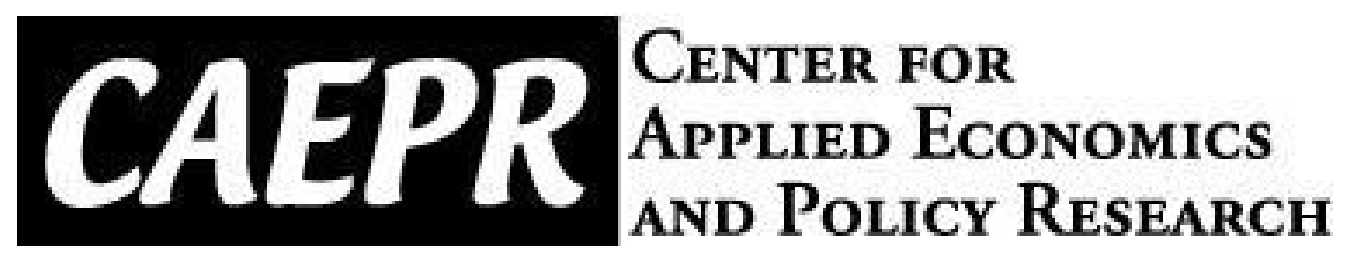

\author{
CAEPR \\ Working Paper \\ \#2020-006
}

Fiscal Stress and Monetary Policy Stance in Oil-Exporting Countries

\author{
Hao Jin \\ Xiamen University \\ Chen Xiong \\ Xiamen University
}

July 2020

This paper can be downloaded without charge from the Social Science Research

Network electronic library at

https://papers.ssrn.com/sol3/papers.cfm?abstract_id=3651014

The Center for Applied Economics and Policy Research resides in the Department of Economics at Indiana University Bloomington. CAEPR can be found on the Internet at: http://www.indiana.edu/ caepr. CAEPR can be reached via email at caepr@indiana.edu or via phone at 812-855-4050.

(C)2020 by Hao Jin and Chen Xiong. All rights reserved. Short sections of text, not to exceed two paragraphs, may be quoted without explicit permission provided that full credit, including (C) notice, is given to the source. 


\title{
Fiscal Stress and Monetary Policy Stance in Oil-Exporting Countries*
}

\author{
Hao $\operatorname{Jin}^{\dagger}$ \\ Xiamen University \\ Chen Xiong ${ }^{\ddagger}$ \\ Xiamen University
}

\begin{abstract}
We documented that for some oil-exporting countries, the correlation between exchange rates and oil prices is strongly negative during periods of significant oil price drop but is much weaker during other periods. To interpret this time-varying asymmetric correlation, we develop and estimate a Markov-switching small open economy New Keynesian model with oil income as a source of government revenue. In particular, we allow monetary and fiscal policy coefficients to switch across "active" and "passive" regimes. Using data on Russia, our result shows that the policy combinations fluctuate. We find that active monetary policy isolates the exchange rate from oil price variations but changes to passively tolerate depreciation and inflation to support government debt when oil price drops place fiscal policy in a state of stress. Counterfactual policy experiments suggest policy regime switching is crucial to account for the observed asymmetric impact of oil prices on the exchange rate and that the transmission channels of oil price shocks differ significantly across policy regimes.
\end{abstract}

Keywords: Fiscal Policy; Monetary Policy; Exchange Rate; Oil Price.

JEL Classification: E52, E63, F41, Q43

*We would like to thank two anonymous referees, as well as seminar and conference participants at the 5th HenU/INFER Workshop on Applied Macroeconomics, the 2019 Asian Meeting of the Econometrics Society, the Tsinghua Workshop in International Finance 2019, and Xiamen University for their helpful comments. Jin acknowledges financial support from the Fundamental Research Funds for the Central Universities 20720171075. All errors are our own.

${ }^{\dagger}$ Wang Yanan Institute for Studies in Economics and the Department of International Economics and Trade, School of Economics, Xiamen University. Email: haojin.econ@gmail.com

${ }^{\ddagger}$ Wang Yanan Institute for Studies in Economics, Xiamen University. 


\section{INTRODUCTION}

A large volume of empirical studies have found that oil price variations have an important effect on economic dynamics for small oil-exporting countries. However, whether and how the impact varies over time received less attention. Figure 1 plots the dynamics of oil prices and exchange rates for six oil-exporting countries. The shaded areas indicate two periods of significant oil price drop. ${ }^{1}$ We can see that oil price changes are associated with substantial exchange rate movements during these two periods, but not during other periods, except for Norway. Table 1 further reports the statistical relationship between oil prices and exchange rates across different periods. It is evident that the correlation between exchange rates and oil prices varies substantially over time, which is highly negative for all countries during sharp oil-price-drop periods and becomes much weaker, or even positive, for all sample countries except Norway during other periods. ${ }^{2}$ A natural question then is why the effect of oil price variations is asymmetric across different periods for some oil-exporting countries?
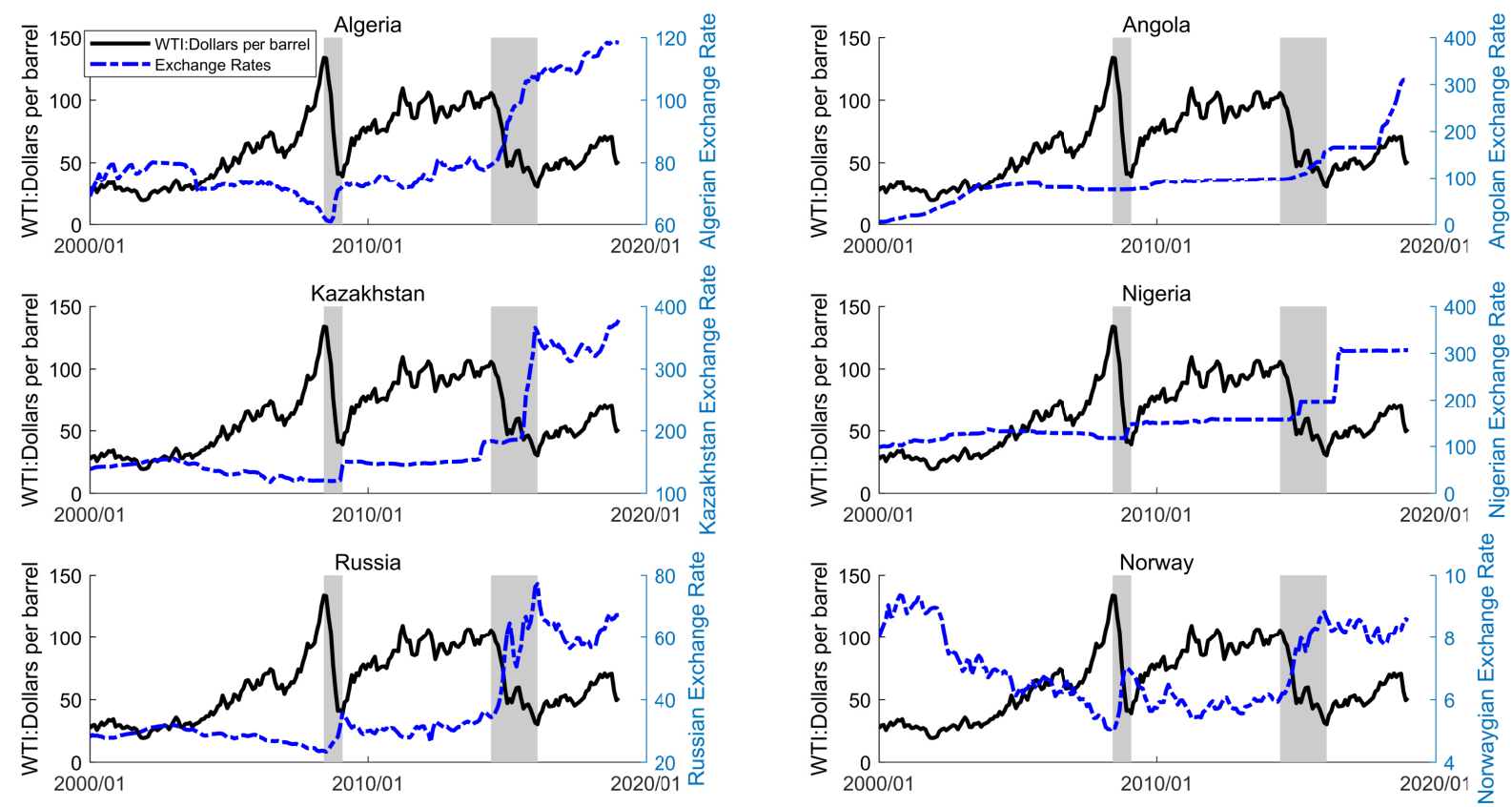

Figure 1: Oil Prices and Exchange Rates

A commonly held view for this time-varying asymmetric impact of oil prices on exchange rates for oil-exporting countries is that they adopt managed floating exchange rate arrangements during normal times; however, oil price plunges generate

\footnotetext{
${ }^{1}$ In these two periods, the West Texas Intermediate (WTI) crude oil prices fell by more than $70 \%$ over the course of 9 months and 21 months respectively.

${ }^{2}$ Although not reported, the correlation from Brazil is similar to that from Norway.
} 
Table 1: Correlation between Oil Prices and Exchange Rates

\begin{tabular}{lccc}
\hline \hline & $2008 / 06-2009 / 02$ & $2014 / 06-2016 / 02$ & Other Times \\
\cline { 2 - 4 } Algeria & -0.90 & -0.93 & -0.16 \\
Angola & -0.74 & -0.78 & 0.24 \\
Kazakhstan & -0.43 & -0.63 & -0.12 \\
Nigeria & -0.70 & -0.84 & 0.08 \\
Russia & -0.85 & -0.97 & -0.12 \\
Norway & -0.98 & -0.97 & -0.78 \\
\hline
\end{tabular}

fiscal stress and constrain the ability of monetary policy to stabilize exchange rates and the economy. ${ }^{1}$ To see the fiscal stress created by lower oil prices, figure 2 shows that oil income accounts for more than $50 \%$ of fiscal revenue and that the fall of oil income significantly drives down fiscal revenue for the sample countries. ${ }^{2}$ In contrast, oil price variations cause a time-invariant symmetric effect on exchange rates for oil exporters under a free-floating system, such as that seen in Norway. Therefore, taking into account the role of monetary and fiscal policy interactions in transmitting oil price shocks seems crucial to explain the business cycle dynamics for these countries. However, the existing literature has not yet provided a formal quantitative evaluation of this view. In this paper, we attempt to take this task.

In particular, we develop and estimate a Markov-switching small open economy New Keynesian dynamic stochastic general equilibrium (DSGE) model with oil income as a source of government revenue. In our framework, the government collects tax revenue from oil production in foreign currency and issues long-term debt in domestic currency to finance its domestic currency expenditures. Importantly, to quantitatively analyze the role of monetary and fiscal policy interaction in transmitting oil price shocks, we allow the monetary and fiscal policy regime to switch stochastically. When oil prices are high, the budget perspective is bright, and investors expect future budget surplus is sufficient to retire government debt. The ample fiscal space in turn accommodates monetary policy to actively target exchange rate movements and inflation. We follow the terminology developed by Leeper (1991) to label this policy combination as "active monetary/passive fiscal" (AM/PF). On the contrary, lower oil prices adversely influence the fiscal budget, and investors expect that fiscal policy will be unable to adjust to repay government debt. In this case, monetary policy is restricted by fiscal policy and has to allow higher inflation to reduce the real value of outstanding government debt denominated in domestic currency, and exchange rate

\footnotetext{
${ }^{1}$ See for example Economist (2015).

${ }^{2}$ We do not present the fiscal revenue of Angola due to data availability.
} 

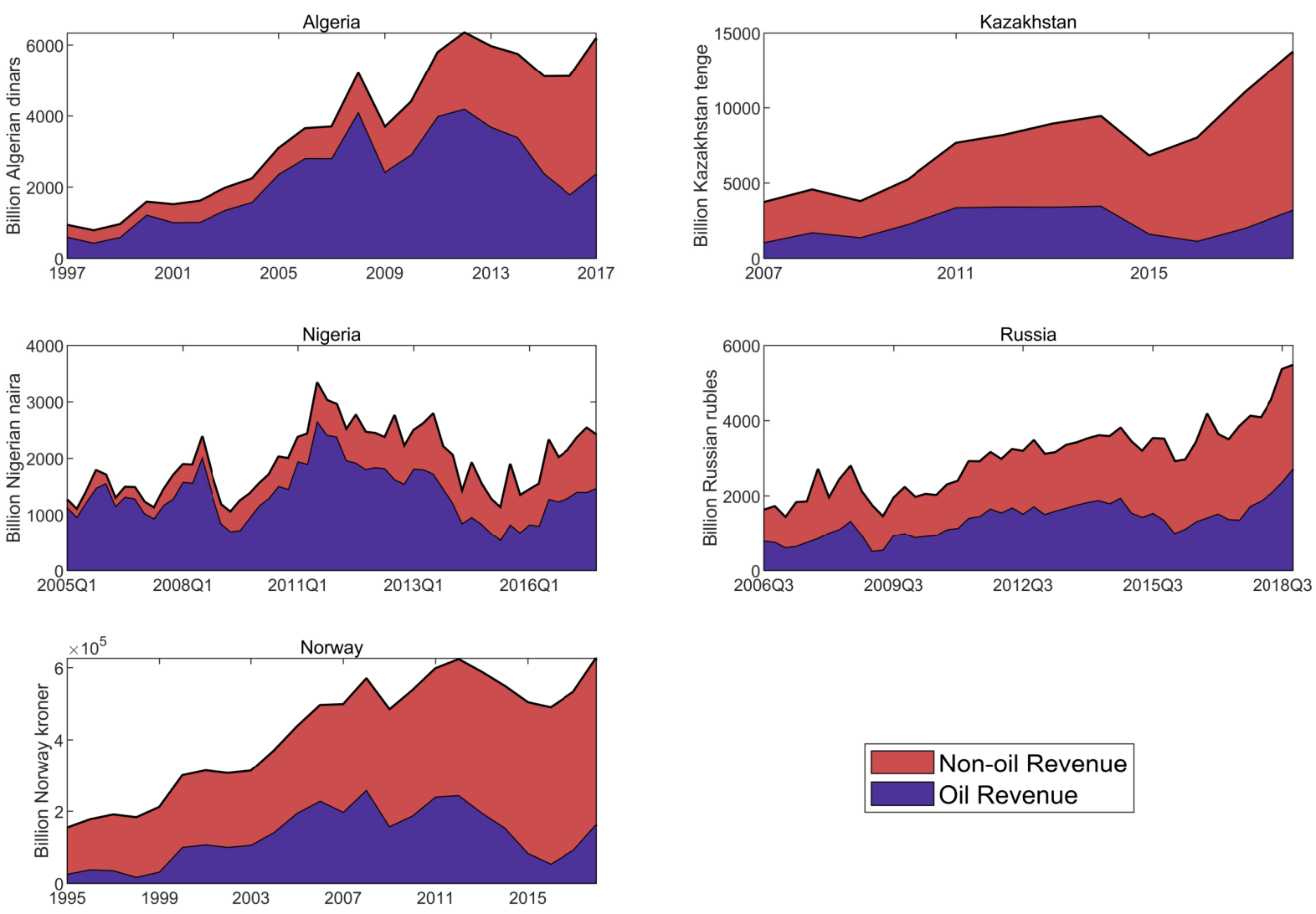

Figure 2: Oil Income and Fiscal Stress

depreciation to increase the relative value of foreign-currency-denomiated oil income against domestic-currency-denominated government expenditures. We label this policy configuration as "passive monetary/active fiscal" (PM/AF). In addition, we follow Bianchi (2012), Bhattarai et al. (2016), and Bianchi and Ilut (2017) to permit "active monetary/active fiscal" (AM/AF) and "passive monetary/passive fiscal" (PM/PF) regimes in the estimation. To perform sensible quantitative evaluation, our model also features consumption habit formation, endogenous capital utilization, real frictions, sticky prices and wages, and various shocks.

We estimate our model to Russia, a prototype oil exporter that manages its exchange rate and heavily relies on petroleum revenue to finance government expenditures. We find that monetary and fiscal policy regimes fluctuate over the sample period. During most of the sample period, the monetary policy is in the active regime, but it switches to the passive regime during periods of substantial oil price falls. Narrative evidence from the central bank of Russia suggests that the model-inferred policy regime switching periods correspond to stated changes of monetary policy. In particular, Russia increased the operational band of its managed floating exchange rate frame- 
work in late 2008 and attributed the reason to sharp changes in the global commodity markets. In November 2014, Russia cancelled the operational band for exchange rate interventions. We also perform counterfactural policy experiments to examine the importance of monetary and fiscal policy regime switching in producing the asymmetric relationship between exchange rates and oil prices over time. We find that conditional on the AM/PF regime over the oil price plunge period, the model generates only a weak correlation, which is inconsistent with the data.

Our estimation result shows that the macroeconomic stability implications differ across policy regimes. Theoretical variance decomposition suggests that the oil prices shocks contribute more to the volatilities of macroeconomic variables under the PM/AF regime relative to that under the $\mathrm{AM} / \mathrm{PF}$ regime. As a result, ignoring the policy regime switching may lead to misguided conclusion on the main drivers of business cycles.

Moreover, the transmission channels of oil price variations on the macroeconomic variables vary significantly conditional on different policy combinations. A fall of oil price generates budget and trade deficits. In the AM/PF regime, the government is able to raise tax revenue in response to higher government debt and monetary policy can keep the exchange rate and inflation stable. As a result, real interest rate rises significantly. This in turn amplifies the initial negative oil price shock. On the other hand, in the PM/AF regime, monetary and fiscal policy jointly determine the macroeconomic dynamics and the price level. A negative oil price shock is inflationary and depreciationary. Since the nominal interest rate only weakly increases in response to the rise of inflation and exchange rate in this regime, real interest rate falls and real exchange rate depreciates significantly. These real price adjustments mitigate the unfavorable oil price shock. Thus, our result suggests the importance of considering policy regime switching when examine the impact of oil price shocks for oil-exporting countries.

\section{LiterATURE REVIEW}

Our work belongs to the literature that analyzes the effect of monetary and fiscal policy in transmitting external shocks for open economies. Many studies have been devoted to examining the role of monetary policy and exchange rate regimes. For example, Broda (2004), Edwards and Yeyati (2005), and Devereux et al. (2006) demonstrate that the impacts of external shocks vary substantially across different exchange rate regimes. ${ }^{1}$ But most of these papers ignore the role played by fiscal policy. On

\footnotetext{
${ }^{1}$ Medina et al. (2005) and Hou et al. (2016) specifically focus on the effect of monetary policy on transmitting external oil price shocks.
} 
the other hand, Pieschacón (2012), Berg et al. (2013), and García-Cicco and Kawamura (2015) find that fiscal policies are useful to stabilize macroeconomic variables for oilexporting countries subject to oil price shocks. However, they assume fiscal policy is always capable to sustain the government debt and monetary policy is unconstrained to pursue its targets. We contribute to the literature by taking into consideration the interactions between monetary and fiscal policy when assessing the impacts and transmission channels of oil price shocks. We show that different policy combinations are crucial to understanding the asymmetric effect of oil price shocks on exchange rates and the business cycle fluctuations across different time periods.

This paper is also related to the strand of literature on monetary and fiscal policy interactions. Pioneer contributions such as Leeper (1991), Woodford (1996), and Cochrane (2001) show that inflation targeting monetary policy requires fiscal backing. Otherwise the price level is jointly determined by fiscal policy and monetary policy. Burnside et al. (2001), Daniel (2001), and Corsetti and Maćkowiak (2006) integrate the theory of monetary and fiscal interactions and the insight gained from Krugman (1979)'s currency crises model into a unified dynamic general equilibrium framework. These existing studies focus on explaining and quantifying the effect of fiscal imbalance on price levels, but do not pay attention to the business cycle dynamics. We extend their framework to include production, real frictions, and nominal rigidities in order to quantitatively evaluate the impacts of monetary and fiscal policy interactions on macroeconomic and currency stability.

In addition, instead of splitting the data conditional on conjectured policy regimes, we allow policies to switch regimes and make estimates for the entire sample period. In this regard, our paper is related to work on Markov-switching DSGE model estimation; see for example, Sims and Zha (2006), Liu et al. (2011), Bianchi (2012), Baele et al. (2015), and Bjørnland et al. (2018). But unlike our work, the existing studies only consider regime switching in monetary policy and the volatility of shocks, not joint regime switching in both monetary and fiscal policy. ${ }^{1}$ We find that taking into account fiscal policy behavior is critical in identifying the policy rule parameters and greatly alters the transmission mechanism of oil price shocks.

\section{MODEL}

In this section, we lay out a two-sector small open economy New Keynesian model. The model incorporates an oil production sector, whose products will be exported,

\footnotetext{
${ }^{1}$ Notable exceptions include Kliem et al. (2016), Bhattarai et al. (2016), and Bianchi and Ilut (2017) who consider monetary and fiscal policy interactions in closed economies.
} 
and the government collects tax revenue from oil production. Moreover, we allow the monetary and fiscal policy rules to jointly switch regimes according to the region of policy rule coefficients.

\subsection{PRODUCERS}

3.1.1 Non-OIl SECTOR Final GoOds PRODUCER The final goods producer in the non-oil sector combines differentiated intermediate goods to manufacture a homogeneous product that can be used in consumption, investment, and export. The bundle technology is given by:

$$
Y_{t}=\left[\int_{0}^{1} Y_{t}(i)^{\frac{1}{\lambda_{d}}} d i\right]^{\lambda_{d}},
$$

where $Y_{t}$ and $Y_{t}(i)$ denote final output and intermediate goods $i$ inputs, respectively. $\lambda_{d}$ measures the elasticity of substitution between different intermediate goods.

The final goods producer operates in perfectly competitive input and output markets. The producer maximizes profits by choosing the non-oil intermediate inputs $Y_{t}(i)$, taken as given the output prices $P_{t}$ and input prices $P_{t}(i)$. The first-order condition gives the following demand function:

$$
Y_{t}(i)=\left[\frac{P_{t}(i)}{P_{t}}\right]^{\frac{\lambda_{d}}{1-\lambda_{d}}} Y_{t}
$$

Plugging the demand function (3.2) to the bundle technology (3.1) yields the final goods aggregate price index:

$$
P_{t}=\left[\int_{0}^{1} P_{t}(i)^{\frac{1}{1-\lambda_{d}}} d i\right]^{1-\lambda_{d}}
$$

3.1.2 NON-OIL SEctor Intermediate GoOds Producer A continuum of intermediate goods producers manufacture differentiated non-oil goods using the following technology:

$$
Y_{t}(i)=Z_{t} K_{N O, t}(i)^{\alpha} H_{N O, t}(i)^{1-\alpha}-\phi,
$$

where $K_{N O, t}(i)$ and $H_{N O, t}(i)$ are capital and labor inputs utilized by the non-oil goods producers, respectively. The aggregation of capital goods and labor are given by $K_{N O, t}=$ $\int_{0}^{1} K_{N O}(i)$ and $H_{N O, t}=\int_{0}^{1} H_{N O, t}(i) . Z_{t}$ is the economy-wide productivity level. We introduce a fixed cost $\phi$ to ensure that the producers receive zero profits in the steady 
state.

The productivity follows an $\mathrm{AR}(1)$ process given by:

$$
\ln \left(\frac{Z_{t}}{Z}\right)=\rho_{z} \ln \left(\frac{Z_{t-1}}{Z}\right)+\varepsilon_{t}^{z},
$$

where $Z$ is the steady state productivity level and $\varepsilon_{t}^{z} \sim N\left(0, \sigma_{z}\right)$.

The intermediate non-oil goods producers minimize the cost of inputs:

$$
\min _{K_{t}(i), H_{t}(i)} W_{t} H_{N O, t}(i)+R_{N O, t}^{k} K_{N O, t}(i),
$$

subject to the production technology (3.4), taken as given sector-specific capital rental rate $R_{N O, t}^{k}$ and the economy-wide labor wage rate $W_{t}$.

The first-order conditions are given by:

$$
\frac{W_{t}}{R_{N O, t}^{k}}=\frac{1-\alpha}{\alpha} \frac{K_{N O, t}(i)}{H_{N O, t}(i)} .
$$

The optimality conditions imply the intermediate goods producers choose the same quantity of inputs, so we can rewrite these conditions as:

$$
\frac{w_{t}}{r_{N O, t}^{k}}=\frac{1-\alpha}{\alpha} \frac{K_{N O, t}}{H_{N O, t}}
$$

where $w_{t}$ and $r_{N O, t}^{k}$ are real wage rate and capital rental rate, respectively.

Substitute the first-order conditions to the production function (3.4) to obtain the expressions for the factor of inputs. Using these expressions in the cost function (3.6) yields the following marginal costs:

$$
m c_{t}=\left(\frac{1}{1-\alpha}\right)^{1-\alpha}\left(\frac{1}{\alpha}\right)^{\alpha}\left(r_{N O, t}^{k}\right)^{\alpha} w_{t}^{1-\alpha} \frac{1}{Z_{t}} .
$$

We assume the intermediate goods producers are the monopolistic supplier of differentiated goods, so they set the prices of their products according to Calvo (1983). The Calvo pricing implies that in any period, each producer has a probability of (1$\xi_{d}$ ) of re-optimizing its prices. The producers index their prices following the simple rule below when they cannot re-optimize:

$$
P_{t}(i)=\tilde{\pi}_{d, t} P_{t-1}(i),
$$

where we define $\tilde{\pi}_{d, t} \equiv \pi_{t-1}^{\kappa_{d}} \pi^{1-\kappa_{d}}$. We let $\pi_{t} \equiv P_{t} / P_{t-1}$ to denote the current period 
inflation rate and $\pi$ to denote the steady-state inflation rate. As a result the pricing rule (3.10) implies the current price is partially indexed to the inflation rate of the last period.

The pricing decisions imply the following aggregate price index:

$$
P_{t}=\left[\xi_{d}\left(\tilde{\pi}_{d, t} P_{t-1}\right)^{\frac{1}{1-\lambda_{d}}}+\left(1-\xi_{d}\right)\left(P_{t}^{n}\right)^{\frac{1}{1-\lambda_{d}}}\right]^{1-\lambda_{d}},
$$

where $P_{t}^{n}$ denotes the chosen price after re-optimization.

3.1.3 Oil Sector Producers Firms in the oil sector employ capital $K_{O, t}$, labor $H_{O, t}$, and nature oil resource $O_{t}$ to produce oil products. We assume all oil products are export to the rest of the world and the price is denominated in foreign currency. The oil resource is exogenously endowed:

$$
\ln \left(\frac{O_{t}}{O}\right)=\rho_{O} \ln \left(\frac{O_{t-1}}{O}\right)+\varepsilon_{t}^{O Y},
$$

where $O$ denotes the steady state oil resource level, and $\varepsilon_{t}^{O Y} \sim N\left(0, \sigma_{O Y}\right)$. Since we do not explicitly model the external demand for oil products, we assume the oil price is exogenous and follows an $\mathrm{AR}(1)$ process:

$$
\ln \left(\frac{P_{t}^{O}}{P^{O}}\right)=\rho_{O P} \ln \left(\frac{P_{t-1}^{O}}{P^{O}}\right)+\varepsilon_{t}^{O P},
$$

where $P^{O}$ denotes the steady state level of oil prices and $\varepsilon_{t}^{O P} \sim N\left(0, \sigma_{O P}\right)$. We interpret the shocks to the oil prices $\varepsilon_{t}^{O P}$ as variations of world oil demand and supply, which we consider exogenous in our model.

Taken oil prices as given, the oil production firms choose inputs to maximize profits:

$$
\max _{K_{O, t}, H_{O, t}}\left(1-\tau^{O}\right) S_{t} P_{t}^{*} P_{t}^{O} Y_{t}^{O}-W_{t} H_{O, t}-R_{O, t}^{k} K_{O, t}
$$

subject to the following technology:

$$
Y_{t}^{O}=Z_{t}\left(K_{O, t}\right)^{\alpha_{O}}\left(H_{O, t}\right)^{\chi_{O}} O_{t}^{1-\alpha_{O}-\chi_{O}},
$$

where $S_{t}$ denotes the nominal exchange rate, $P_{t}^{*}$ denotes the import goods price, $\tau^{O}$ denotes the tax rate on oil revenue, and $R_{O, t}^{k}$ is the oil sector capital rental rate.

We define the real exchange rate $\tilde{S}_{t} \equiv S_{t} P_{t}^{*} / P_{t}$. Then the optimality conditions 
imply:

$$
w_{t}=\left(1-\tau^{O}\right) \tilde{S}_{t} \chi_{O} Z_{t}\left(K_{O, t}\right)^{\alpha_{O}}\left(H_{O, t}\right)^{\chi_{O}-1} O_{t}^{1-\alpha_{O}-\chi_{O}},
$$

and

$$
r_{O, t}^{k}=\left(1-\tau^{O}\right) \tilde{S}_{t} \alpha_{O} Z_{t}\left(K_{O, t}\right)^{\alpha_{O}-1}\left(H_{O, t}\right)^{\chi_{O}} O_{t}^{1-\alpha_{O}-\chi_{O}} .
$$

3.1.4 EXPORTER The country also exports non-oil final goods to the rest of the world. We assume the demand for these exports is given by:

$$
X_{t}=\left(\frac{1}{\tilde{S}_{t}}\right)^{-\eta_{f}} Y_{t}^{*}
$$

where $Y_{t}^{*}$ denotes foreign output level and $\eta_{f}$ measures the elasticity of substitution between exported non-oil goods and foreign goods.

3.1.5 CAPITAL PRODUCER A representative capital producer purchases investment goods and undepreciated capital goods at the end of period $t-1$ and combines them into new capital goods in period $t$. We assume the oil sector and the non-oil sector have their sector-specific investment and capital goods. The evolution of capital goods is given by:

$$
e_{n}^{\prime}=e_{n}+F\left(I_{n, t}, I_{n, t-1}\right)=e_{n}+\left[1-s\left(\frac{I_{n, t}}{I_{n, t-1}}\right)\right] I_{n, t},
$$

where we denote the undepreciated and new capital goods as $e_{n}$ and $e_{n}^{\prime}$, respectively. $n \in\{N O, O\}$ is a sector identifier, $F(\cdot)$ denotes the production technology and $s(\cdot)$ denotes capital adjustment costs. Following Christiano et al. (2005), $s(\cdot)$ satisfies $s(1)=$ $s^{\prime}(1)=0$, and $s^{\prime \prime}(1)>0$, which implies the adjustment costs increase with the rate of new investment.

We denote the capital price as $Q_{n, t}$, the investment good price as $P_{i, t}$, such that the profit of the capital producer in period $t$ is given by:

$$
\Pi_{k, n, t}=Q_{n, t}\left[e_{n}+F\left(I_{n, t}, I_{n, t-1}\right)\right]-Q_{n, t} e_{n}-P_{i, t} I_{n, t} .
$$

The capital producer chooses $e_{n}$ and $I_{n, t}$ to maximize the following objective function:

$$
\max _{e_{n, t+j}, I_{n, t+j}} E_{t} \sum_{j=0}^{\infty}\left\{\beta^{j} v_{t+j} \Pi_{k, n, t+j}\right\}
$$

where $v_{t}$ denotes the marginal utility of consumption for households. Since $e_{n}$ is indetermined from the maximization problem, we set $e_{n}=(1-\delta) \bar{K}_{n, t}$, where $\bar{K}_{n, t}$ denotes the capital stock in the economy. 
$I_{t}$ is a composite of final investment goods that combines domestic and foreign investment goods using the following CES technology:

$$
I_{t}=\left[\left(1-\omega_{i}\right)^{\frac{1}{\eta_{i}}} \frac{\eta_{i}-1}{I_{H, t}}+\omega_{i}^{\frac{1}{\eta_{i}}} I_{F, t}^{\frac{\eta_{i}-1}{\eta_{i}}}\right]^{\frac{\eta_{i}}{\eta_{i}-1}},
$$

where $\eta_{i}$ measures the elasticity of substitution between home and foreign investment goods and $\omega_{i}$ controls the share of imported goods.

The optimality conditions imply the following demand functions for investment goods:

$$
I_{H, t}=\left(1-\omega_{i}\right)\left(\frac{P_{t}}{P_{i, t}}\right)^{-\eta_{i}}\left(I_{t}+a\left(u_{N O, t}\right) \bar{K}_{N O, t}+a\left(u_{O, t}\right) \bar{K}_{O, t}\right),
$$

and

$$
I_{F, t}=\left(1-\omega_{i}\right)\left(\frac{P_{t}^{F}}{P_{i, t}}\right)^{-\eta_{i}}\left(I_{t}+a\left(u_{N O, t}\right) \bar{K}_{N O, t}+a\left(u_{O, t}\right) \bar{K}_{O, t}\right),
$$

where $a\left(u_{n, t}\right) \bar{K}_{n, t}$ denotes that the utilization cost in terms of investment goods, which we will describe later.

The aggregate investment price index is given by:

$$
P_{i, t}=\left[\left(1-\omega_{i}\right)\left(P_{t}\right)^{1-\eta_{i}}+\omega_{i}\left(P_{t}^{F}\right)^{1-\eta_{i}}\right]^{\frac{1}{1-\eta_{i}}},
$$

where the import price $P_{t}^{F}=P_{t}^{*} S_{t}$.

3.2 HouseHolds A continuum of households in this small open economy maximizes lifetime utility:

$$
E_{t} \sum_{k=0}^{\infty} \beta^{k}\left[\zeta_{c, t} \ln \left(C_{j, t+k}-b C_{j, t+k-1}\right)-A_{L} \frac{\left(h_{j, t+k}\right)^{1+\sigma_{L}}}{1+\sigma_{L}}\right],
$$

where $C_{j, t+l}$ and $h_{j, t+l}$ denote consumption and labor choice for household $j . \zeta_{c, t}$ denotes a preference shock given by:

$$
\ln \left(\frac{\zeta_{c, t}}{\zeta_{c}}\right)=\rho_{\zeta_{c}} \ln \left(\frac{\zeta_{c, t-1}}{\zeta_{c}}\right)+\varepsilon_{t}^{\zeta_{c}}
$$

where $\varepsilon_{t}^{\zeta_{c}} \sim N\left(0, \sigma_{\zeta_{c}}\right)$.

$C_{j, t+k}$ is a composite of final consumption goods that combines domestic and for- 
eign consumption goods using the following CES technology:

$$
C_{t}=\left[\left(1-\omega_{c}\right)^{\frac{1}{\eta_{c}}} C_{H, t}^{\frac{\eta_{c}-1}{\eta_{c}}}+\omega_{C}^{\frac{1}{\eta_{c}}} C_{F, t}^{\frac{\eta_{c}-1}{\eta_{c}}}\right]^{\frac{\eta_{c}}{\eta_{c}-1}},
$$

where $\eta_{c}$ measures the elasticity of substitution between home and foreign consumption goods and $\omega_{c}$ controls the share of imported goods in the final consumption bundle.

The optimality conditions imply the following demand functions for consumption goods:

$$
C_{H, t}=\left(1-\omega_{c}\right)\left(\frac{P_{t}}{P_{c, t}}\right)^{-\eta_{c}} C_{t}, \quad C_{F, t}=\omega_{c}\left(\frac{P_{t}^{F}}{P_{c, t}}\right)^{-\eta_{c}} C_{t} .
$$

The aggregate consumption price index is given by:

$$
P_{c, t}=\left[\left(1-\omega_{c}\right)\left(P_{t}\right)^{1-\eta_{c}}+\omega_{c}\left(P_{t}^{F}\right)^{1-\eta_{c}}\right]^{\frac{1}{1-\eta_{c}}},
$$

We assume each household provides differentiated labor to productive firms, and their wage income is given by $W_{j, t} h_{j, t}$. We follow Erceg et al. (2000) to introduce nominal rigidities into the wage setting. To guarantee the existence of a representative household, we assume households can purchase an insurance contract such that the wage income is the same across all households. The net cash flow from the insurance market is $D_{j, t}$.

The $j$ th household's budget constraint is written as:

$$
\begin{aligned}
& P_{c, t} C_{j, t}+S_{t} B_{j, t}^{*}+B_{j, t}+P_{t}^{G} B_{j, t}^{G}+Q_{N O, t} \bar{K}_{N O, t+1}+Q_{O, t} \bar{K}_{O, t+1}= \\
& W_{j, t} h_{j, t}+P_{t} T R_{j, t}+\Pi_{j, t}+S_{t} \Phi_{t-1} R_{t-1}^{*} B_{j, t-1}^{*}+R_{t-1} B_{j, t-1}+R_{E, N O, t} Q_{N O, t} \bar{K}_{N O, t} \\
& +R_{E, O, t} Q_{O, t} \bar{K}_{O, t}+D_{j, t}+\left(1+\rho P_{t}^{G}\right) B_{j, t-1}^{G}
\end{aligned}
$$

where $T R_{j, t}$ denotes the lump-sum transfers/taxes from the government. Because households own the production firms, they obtain $\Pi_{j, t}$ as dividends. $B_{j, t}, B_{j, t}^{*}$ and $B_{j, t}^{G}$ are holdings of domestic private bonds, international bonds, and domestic government bonds, respectively. The households also own capital, so they receive rental income and capital gains each period.

The first-order condition with respect to consumption is given by:

$$
\frac{\zeta_{c, t}}{C_{t}-b C_{t-1}}-\beta \frac{\zeta_{c, t+1}}{C_{t+1}-b C_{t}}-\psi_{z, t} \gamma_{c, t}=0
$$


where $\psi_{z, t}=P_{t} v_{t}$. We denote the relative price of consumption goods as $\gamma_{c, t}=\frac{P_{c, t}}{P_{t}}$, and $v_{t}$ is the Lagrangian multiplier associated with the budget constraint (3.31).

We introduce a utilization rate of capital into the model, denoted by $u_{n, t}$. As a result, the actual use of capital is given by $K_{n, t}=u_{n, t} \bar{K}_{n, t}$. The first order condition with respect to $u_{t}$ implies:

$$
R_{n, t+1}^{k}=a^{\prime}\left(u_{n, t+1}\right) P_{i, t+1},
$$

where $a\left(u_{n}\right)=r_{n}^{k}\left[\exp \left(\sigma_{a}\left(u_{n}-1\right)-1\right)\right] / \sigma_{a, n}$ is the cost associated with adjusting the capital utilization rate, and $\sigma_{a, n}$ is the associated cost parameter.

The capital rate of return $R_{E, n, t+1}$ is given by:

$$
R_{E, n, t+1}=\frac{u_{n, t+1} R_{n, t+1}^{k}-a\left(u_{n, t+1}\right) P_{i, t+1}+\left(1-\delta_{n}\right) Q_{n, t+1}}{Q_{n, t}},
$$

The numerator on the right hand side measures total capital income. The first term represents the rate of return on utilized capital, the second term is the utilization adjustment cost, and the last term is the price of undepreciated capital goods. Dividing the total capital income by the unit replacement cost of capital $Q_{n, t}$ gives the capital rate of return.

The first-order condition with respect to capital goods is given by:

$$
\psi_{z, t}=\beta E_{t}\left[\frac{\psi_{z, t+1} R_{E, N O, t}}{\pi_{t+1}}\right] .
$$

and

$$
\psi_{z, t}=\beta E_{t}\left[\frac{\psi_{z, t+1} R_{E, O, t}}{\pi_{t+1}}\right] .
$$

We introduce long-term bonds into the government debt $B_{t}^{G}$. This is because Cochrane (2001), Daniel (2001), and Corsetti and Maćkowiak (2006) show that long-term government debt is essential to produce the delayed effect of fiscal shocks as observed in the data. Specifically, each period the bond pays a coupon rate $0 \leq \rho \leq 1$, which controls the maturity of outstanding debt, and has a current price $P_{t}^{G}$.

We let $R_{t}$ and $R_{t}^{*}$ represent the domestic and international interest rates, respectively. We follow Schmitt-Grohé and Uribe (2003), Garcia-Cicco et al. (2010), and Chang et al. (2015) to introduce a debt-elastic country risk-premium $\Phi_{t}$, which is given by:

$$
\Phi_{t}=\Phi\left(n f a_{t}\right)=\exp \left(-\phi_{a}\left(n f a_{t}-n f a\right)+\phi_{t}\right)
$$


where $n f a_{t}=S_{t} B_{t}^{*} / P_{t}$ denotes the real net foreign asset position, and $\phi_{t}$ denotes the risk-premium shocks.

The optimality conditions with respect to domestic private bonds and government long-term bonds are given by:

$$
\psi_{z, t}=\beta E_{t}\left[\frac{\psi_{z, t+1} R_{t}}{\pi_{t+1}}\right]
$$

and

$$
\psi_{z, t}=\beta E_{t}\left[\frac{\psi_{z, t+1}\left(1+\rho P_{t+1}^{G}\right)}{P_{t}^{G} \pi_{t+1}}\right] .
$$

Combining the first-order conditions with respect to short-term and long-term bonds yields:

$$
P_{t}^{G}=\mathbb{E}_{t}\left(1+\rho P_{t+1}^{G}\right) \frac{1}{R_{t}},
$$

which is a no-arbitrage condition.

We iterate forward the no-arbitrage condition in $P_{t}^{G}$ and impose a terminal condition to get:

$$
P_{t}^{G}=\mathbb{E}_{t} \frac{1}{R_{t}}\left(1+\sum_{i=1}^{\infty} \prod_{j=1}^{i} \frac{\rho^{j}}{R_{t+j}}\right) .
$$

This equation represents the expectations hypothesis of the term structure of interest rates, which states the long-term rate $P_{t}^{G}$ is determined by the current and future shortterm rates $R_{t+j}$.

The optimality condition with respect to the international bonds is given by:

$$
\psi_{z, t}=\beta E_{t}\left[\frac{\psi_{z, t+1} S_{t+1} \Phi_{t} R_{t}^{*}}{\pi_{t+1}}\right]
$$

where $s_{t} \equiv S_{t} / S_{t-1}$ denotes the appreciation rate of the nominal exchange rate.

3.2.1 Wage Setting A labor packer combines all the differentiated labor into a homogeneous force using the following technology:

$$
H_{t}=\left[\int_{0}^{1} h_{j, t}^{\frac{1}{\lambda w}} d j\right]^{\lambda_{w}}
$$

where $H_{t}$ is the final labor supply to the intermediate goods firms and $\lambda_{w}$ measures the elasticity of substitution between differentiated labor. The labor packer chooses inputs of $h_{j, t}$ to maximize profits, taken as given the $W_{t}$ and $W_{j, t}$. The demand function is given by: 


$$
h_{j, t}=\left(\frac{W_{j, t}}{W_{t}}\right)^{\frac{\lambda_{w}}{1-\lambda_{w}}} H_{t} .
$$

Integrate both sides to obtain the aggregate wage rate:

$$
W_{t}=\left(\int_{0}^{1} W_{j, t}^{\frac{1}{1-\lambda_{w}}} d j\right)^{1-\lambda_{w}}
$$

The households set their labor wage rates according to Calvo (1983). Each period, the households can re-optimize their wage rates with a probability of $\left(1-\xi_{w}\right)$, and the rest of the households set their wage rates following the rule:

$$
W_{j, t}=\tilde{\pi}_{w, t} W_{j, t-1}
$$

where $\tilde{\pi}_{w, t}=\left(\pi_{t-1}\right)^{\kappa_{w}}(\pi)^{1-\kappa_{w}}$.

This implies the aggregate wage rate is given by:

$$
W_{t}=\left[\left(1-\xi_{w}\right)\left(W_{t}^{n}\right)^{\frac{1}{1-\lambda_{w}}}+\xi_{w}\left(W_{t-1} \tilde{\pi}_{w, t}\right)^{\frac{1}{1-\lambda_{w}}}\right]
$$

where $W_{t}^{n}$ is the optimally chosen wage rate.

3.3 MOnetary And Fiscal POlicy The monetary policy instrument is nominal interest rates. We assume the monetary policy obeys a Taylor-type feedback rule. In addition to targeting targeting inflation and output, the monetary policy interest rate also manages the exchange rate by responding to exchange rate changes:

$$
\begin{aligned}
\ln \left(\frac{R_{t}}{R}\right)= & \left(1-\rho_{R}\left(\mathrm{~S}_{\mathbb{M}}\right)\right)\left[r_{\pi}\left(\mathrm{S}_{\mathbb{M}}\right) \ln \left(\frac{\pi_{t}}{\pi}\right)+r_{y}\left(\mathrm{~S}_{\mathbb{M}}\right) \ln \left(\frac{y_{t}}{y}\right)+r_{s}\left(\mathrm{~S}_{\mathbb{M}}\right) \ln \left(s_{t}\right)\right] \\
& +\rho_{R}\left(\mathrm{~S}_{\mathbb{M}}\right) \ln \left(\frac{R_{t-1}}{R}\right)+\varepsilon_{t}^{R}
\end{aligned}
$$

where $\varepsilon_{t}^{R} \sim N\left(0, \sigma_{\varepsilon_{r}}\right)$ denotes the monetary policy shocks. The feedback from exchange rate to monetary policy interest rate captures, in a reduced-form way, the managed floating exchange rate arrangement adopted by many oil-exporting countries. We denote the monetary policy regime by $\mathrm{S}_{\mathbb{M}}$.

Next, we turn to specify fiscal policies. We assume the government expenditure follows an $\mathrm{AR}(1)$ process:

$$
\ln \left(\frac{G_{t}}{\bar{G}}\right)=\rho_{g} \ln \left(\frac{G_{t-1}}{\bar{G}}\right)+\varepsilon_{t}^{g},
$$


where $\varepsilon_{t}^{g} \sim N\left(0, \sigma_{g}\right)$ denotes government expenditure shocks.

The lump-sum transfers/taxes obey the following feedback policy rule:

$$
\ln \left(\frac{T R_{t}}{T R}\right)=\rho_{T}\left(\mathbf{S}_{\mathbb{F}}\right) \ln \left(\frac{T R_{t-1}}{T R}\right)+\left(1-\rho_{T}\left(\mathbf{S}_{\mathbb{F}}\right)\right)\left[\phi_{T}\left(\mathbf{S}_{\mathbb{F}}\right) \ln \left(\frac{b y_{t-1}}{b y}\right)\right],
$$

where $b y_{t-1} \equiv P_{t-1}^{G} B_{t-1}^{G} / Y_{t-1}$ denotes the outstanding-government-debt-to-GDP ratio, and $\mathrm{S}_{\mathbb{F}}$ denotes the fiscal policy regime.

We allow the monetary and fiscal policy coefficients to switch between two regimes given by:

$$
\mathrm{S}_{\mathbb{M}} \in\{A M, P M\}, \mathrm{S}_{\mathbb{F}} \in\{A F, P F\} .
$$

In particular, when we specify the prior for policy coefficients, we follow Bianchi (2012), Bhattarai et al. (2016), and Bianchi and Ilut (2017) to set more aggressive monetary policy response coefficients to inflation and exchange rates under the AM regime relative to those under the PM regime. ${ }^{1}$ On the other hand, we choose more aggressive fiscal policy response coefficient to outstanding debt under PF regime relative to that under the AF regime.

Further, we assume the policy response coefficients take on two values and follow Markov chains with constant transition probabilities. The transition matrix is give by:

$$
P=\left[\begin{array}{cc}
1-p_{M P}^{12} & p_{M P}^{12} \\
p_{M P}^{21} & 1-p_{M P}^{21}
\end{array}\right], \quad Q=\left[\begin{array}{cc}
1-q_{F P}^{12} & q_{F P}^{12} \\
q_{F P}^{21} & 1-q_{F P}^{21}
\end{array}\right]
$$

where $p_{M P}^{12}$ and $p_{M P}^{21}$ denote the probability of switching from the AM regime to the $\mathrm{PM}$ regime and from the PM regime to the AM regime respectively. We let $q_{F P}^{12}$ and $q_{M F}^{21}$ denote the probability of switching from the AF regime to the PF regime and from the $\mathrm{PF}$ regime to the AF regime respectively.

3.4 Government The government collects tax revenue from the sale of oil products, spends on public consumption, and makes lump-sum transfers to the households. It issues long-term debt $B_{t}^{G}$ to finance the budget deficit. The government's budget constraint is written as:

$$
P_{t}^{G} B_{t}^{G}-\left(1+\rho P_{t}^{G}\right) B_{t-1}^{G}+\tau^{O}\left(S_{t} P_{t}^{*} P_{t}^{O} Y_{t}^{O}\right)=P_{t} G_{t}-P_{t} T R_{t},
$$

\footnotetext{
${ }^{1}$ Their framework is for closed economy, so they do not have the response coefficient to exchange rates.
} 
where we assume the tax rate on oil income $\tau^{O}$ is a constant given by the long-run average of the data.

Dividing both sides of the government budget constraint (3.53) by $P_{t}$ and using the no-arbitrage condition (3.40) yield:

$$
\frac{1+\rho P_{t}^{G}}{P_{t}} B_{t-1}^{G}=\tau^{O}\left(\tilde{S}_{t} P_{t}^{O} Y_{t}^{O}\right)+T R_{t}-G_{t}+\frac{1+\rho P_{t+1}^{G}}{P_{t+1}} \frac{1}{r_{t}} B_{t}^{G}
$$

where we denote the real interest rate $r_{t} \equiv R_{t} / \pi_{t+1}$.

Iterating forward on $\left(1+\rho P_{t+1}^{G}\right) B_{t}^{G} / P_{t+1}$ and imposing a transversality condition yield the following intertemporal budget constraint:

$$
\frac{1+\rho P_{t}^{G}}{P_{t}} B_{t-1}^{G}=\sum_{i=1}^{\infty} \prod_{j=1}^{i} \frac{1}{r_{t+j}}\left(\tau^{O} \tilde{S}_{t+i} P_{t+i}^{O} Y_{t+i}^{O}+T R_{t+i}-G_{t+i}\right) .
$$

This intertemporal condition is key to understanding the effects of monetary and fiscal policy interactions. Notice that the left-hand side is the total value of outstanding government debt in period $t$ and the right-hand side is the present value of budget surplus.

In response to a negative shock on oil prices $P_{t}^{O}$, the lump-sum transfers $T R_{t+i}$ and the price variables $P_{t}^{G}, P_{t}$, and $\tilde{S}_{t+i}$ can adjust to restore the equilibrium. An increase of $P_{t}$ and a decrease of $P_{t}^{G}$ directly reduce the real value of outstanding government debt, while a real exchange rate $\tilde{S}_{t+i}$ depreciation raises the dollar-denominated oil income against local-currency-denominated government expenditures.

Monetary and fiscal policy jointly determine the adjustment processes of these variables. First, fiscal policy directly controls the lump-sum transfers $/$ taxes $T R_{t+i}$. Second, the no-arbitrage condition between short-term and long-term government bonds (3.41) states that the current and future monetary policy interest rates determine the current price of long-term government debt $P_{t}^{G}$. Third, monetary policy affects the inflation rate, given the price level from the last period, monetary policy then influences the current price level $P_{t}$. Lastly, the uncovered interest rate (UIP) condition suggests that the domestic and foreign interest rate difference determines the nominal exchange rate appreciation rate, and given the inflation rate, determines the real exchange rate $\tilde{S}_{t+i}$.

We now analyze the underlying mechanisms through which different monetary and fiscal policy combinations produce distinct correlation between oil prices and nominal exchange rates. Suppose fiscal policy is passive and able to raise sufficient future revenues to retire public debt, then monetary policy can aggressively controls 
inflation and exchange rates. As a result, oil price variations under this policy regime are not closely related to nominal exchange rate changes. In contrast, when fiscal policy is active and cannot raise enough future revenues to accommodate public debt, monetary policy needs to weakly targeting inflation and nominal exchange rate and allows higher inflation and greater depreciation. These adjustments helps to restore the equality of condition (3.55) by reducing the real value of outstanding government debt and revaluing the future budget surpluses. Consequently, oil price drops is associated with a nominal depreciation. In the quantitative analysis below, we see that this transmission channel carries over to the equilibrium dynamics.

3.5 Foreign VARIABles We assume foreign price level $P_{t}^{*}$ is constant. The foreign interest rate and the foreign output $Y_{t}^{*}$ follows an AR(1) process given by:

$$
\ln \left(\frac{R_{t}^{*}}{R^{*}}\right)=\rho_{R^{*}} \ln \left(\frac{R_{t-1}^{*}}{R^{*}}\right)+\varepsilon_{t}^{R^{*}},
$$

and

$$
\ln \left(\frac{Y_{t}^{*}}{Y^{*}}\right)=\rho_{Y^{*}} \ln \left(\frac{Y_{t-1}^{*}}{Y^{*}}\right)+\varepsilon_{t}^{Y^{*}},
$$

where $\varepsilon_{t}^{R^{*}} \sim N\left(0, \sigma_{R^{*}}\right)$ and $\varepsilon_{t}^{Y^{*}} \sim N\left(0, \sigma_{Y^{*}}\right)$.

3.6 Market Clearing Conditions The non-oil final goods market clears as follows:

$$
Y_{t}=G_{t}+C_{H, t}+I_{H, t}+X_{t} .
$$

The market clearing conditions for investment goods and labor markets are given by:

$$
I_{t}=I_{N O, t}+I_{O, t}
$$

and

$$
H_{t}=H_{N O, t}+H_{O, t}
$$

The balance of payment identity is given by:

$$
S_{t} B_{t}^{*}=P_{t} X_{t}+S_{t} P_{t}^{*} P_{t}^{O} Y_{t}^{O}-S_{t} P_{t}^{*}\left(C_{F, t}+I_{F, t}\right)+R_{t-1}^{*} S_{t} B_{t-1}^{*} \Phi_{t-1}
$$

\section{Quantitative AnAlysis}

In this section, we describe the data used in the quantitative analysis, the calibration strategy, and the prior and posterior distribution for our model parameters. 
Table 2: Calibration of Parameters: Quarterly

\begin{tabular}{llll}
\hline \hline Parameter & Description & Value & Target \\
\hline$\alpha$ & capital share in production & 0.35 & investment share \\
$\delta_{N O}$ & depreciation rate of capital & 0.025 & standard value \\
$\delta_{O}$ & depreciation rate of capital & 0.025 & standard value \\
$\omega_{c}$ & import consumption share & 0.27 & import share \\
$\omega_{i}$ & import investment share & 0.27 & import share \\
$A_{L}$ & labor supply capacity & 8.9 & labor hours \\
$\tau^{O}$ & tax rate of oil income & 0.80 & oil income share \\
$\pi$ & steady-sate inflation & 1.0256 & mean inflation rate \\
$b y$ & government-debt-to-GDP ratio & 0.44 & average debt ratio \\
$\rho$ & government debt maturity & 0.95 & average debt maturity \\
\hline \hline
\end{tabular}

4.1 DATA We parametrize our model using data on Russia from 2003Q1 to 2016Q4. ${ }^{1}$ We include fourteen observables in our data set. They are GDP, consumption, investment, export, import, government spending, government deficit, oil price, oil output, wage rate, inflation rate, foreign interest rate, domestic nominal interest rate, and exchange rate. We measure the macroeconomic quantities in real terms and remove their seasonality.

We take log and use the HP-filter to detrend the following variables: GDP, consumption, investment, export, import, government spending, oil price, oil output, and wage rate. For foreign interest rate, nominal interest rate, and inflation, we subtract their sample mean. We measure government deficit as the deficit ratio of GDP and subtract its sample mean. The exchange rate is measured as the rate of change of the Russian ruble against US dollars. We transform the variables in the model in the same way as we do the data. We describe the data details in Appendix A.

4.2 CALibrated PARAmEters We partition the model parameters into two groups. The first group contains parameters that we calibrate to a fixed value, whereas we estimate the parameters in the second group using Bayesian methods. We present the calibrated and estimated parameter values in tables 2 and 3, respectively.

We calibrate the value of the following parameters to match the first moments in

\footnotetext{
${ }^{1}$ The data are obtained from the Federal Reserve Economic Database. Since several macroeconomic time series, such as the GDP, start from 2003Q1, we choose the sample period to be between 2003Q1 and 2016 Q4.
} 
the data. We set the capital share of intermediate goods production $\alpha$ to 0.35 in order to match the average gross capital-formation-to-GDP ratio, which is 0.2 in the data. We fix the quarterly depreciation rate of capital $\delta$ to 0.025 , which is a standard value in the literature. Over our sample period, the average imports-to-GDP ratio is 0.22 , and to match this moment, we set the import share parameter $\omega_{c}$ and $\omega_{i}$ to 0.27 . The labor supply capacity $A_{L}$ is chosen to match the $1 / 3$ working hours per period. We calculate the oil income share of government by dividing the oil tax income by the total government revenue. The oil tax rate $\tau^{O}$ is then chosen to be 0.8 to match the oil income share of the government. We set the steady-state inflation rate at 1.0256 to match the mean CPI inflation of data. The government debt maturity parameter $\rho$ is set to 0.95 in order to match the average government debt maturity. The steady-state government-debt-to-GDP ratio by is fixed at 0.44 , which equals the average in the data.

4.3 Estimated Parameters And Priors We estimate all the remaining parameters in the model using Bayesian methods. ${ }^{1}$ Table 3 reports the prior and posterior distribution for the estimated structural parameters and the shock parameters.

Following the Bayesian estimation of the MS-DSGE model in Liu et al. (2011) and Bjørnland et al. (2018), instead of specifying the mean and the standard deviation, we use the $90 \%$ probability interval to back out the hyperparameter values of the prior distribution of estimated parameters. This implies our priors are more flexible and cover wider range relative to those in the previous studies. For technical reasons, some of the estimated parameters, such as households discount rate $\beta$, are estimated indirectly via transformations.

We consider priors for policy parameters first. Policy parameters have different prior specifications depending on the regime. Under the AM regime, the monetary policy interest rate reacts strongly to inflation and exchange rate variations, so we let the responsiveness coefficient to inflation $r_{\pi}$ follow a gamma distribution with 1.2 to 1.8 covering the $90 \%$ probability interval, while the responsiveness coefficient to exchange rate variations $r_{s}$ follows a gamma distribution with 0.2 to 2 covering the $90 \%$ probability interval. Under the PM regime, the monetary policy interest rate responds weakly. Thus, we let $r_{\pi}$ follow a gamma distribution with 0.25 to 0.75 covering the $90 \%$ probability interval while $r_{s}$ follows a normal distribution with -0.01 to 0.01 covering the $90 \%$ probability interval. Our prior for $r_{y}$ is the same under both the AM and PM regimes, which follows a gamma distribution with the hyperparameters appropriately chosen such that the bounds for the $90 \%$ probability interval are 0.05 to 0.2 .

\footnotetext{
${ }^{1}$ We use the RISE toolbox developed in Maih (2015) to perform the estimation of our regime switching DSGE model.
} 
Table 3: Model Priors and Posteriors

\begin{tabular}{|c|c|c|c|c|c|c|c|}
\hline \multirow[b]{2}{*}{ Parameter } & \multirow[b]{2}{*}{ Description } & \multicolumn{3}{|c|}{ Prior } & \multicolumn{3}{|c|}{ Posterior } \\
\hline & & dist & $5 \%$ & $95 \%$ & Mode & Mean & $90 \%$ CS \\
\hline$p_{M P}^{12}$ & transition probability & Beta & 0.01 & 0.2 & 0.0132 & 0.0146 & {$[0.0082,0.0218]$} \\
\hline$p_{M P}^{21}$ & transition probability & Beta & 0.01 & 0.2 & 0.0484 & 0.0375 & {$[0.0264,0.0472]$} \\
\hline$q_{F P}^{12}$ & transition probability & Beta & 0.01 & 0.2 & 0.0872 & 0.0971 & {$[0.0813,0.1167]$} \\
\hline$q_{F P}^{21}$ & transition probability & Beta & 0.01 & 0.2 & 0.0477 & 0.041 & {$[0.0335,0.0503]$} \\
\hline$r_{\pi}($ state $\mathrm{AM})$ & coeff. of monetary policy to inflation & Gamma & 1.2 & 1.8 & 1.3631 & 1.3594 & {$[1.3418,1.3734]$} \\
\hline$r_{y}($ state $\mathrm{AM})$ & coeff. of monetary policy to output gap & Gamma & 0.05 & 0.2 & 0.0616 & 0.0685 & {$[0.0555,0.0824]$} \\
\hline$r_{s}($ state $\mathrm{AM})$ & coeff. of monetary policy to exchange rate & Gamma & 0.2 & 2 & 0.6146 & 0.6137 & {$[0.5947,0.6332]$} \\
\hline$r_{\pi}($ state $\mathrm{PM})$ & coeff. of monetary policy to inflation & Beta & 0.25 & 0.75 & 0.3649 & 0.3627 & {$[0.3443,0.3761]$} \\
\hline$r_{y}($ state $\mathrm{PM})$ & coeff. of monetary policy to output gap & Gamma & 0.05 & 0.2 & 0.0816 & 0.0771 & {$[0.0661,0.0909]$} \\
\hline$r_{S}($ state $\mathrm{PM})$ & coeff. of monetary policy to exchange rate & Normal & -0.01 & 0.01 & 0.0024 & 0.0006 & {$[-0.0058,0.0071]$} \\
\hline$\phi_{T}($ state $\mathrm{PF})$ & coeff. of lump-sum tax to debt & Gamma & 0.05 & 0.25 & 0.0827 & 0.0784 & {$[0.0675,0.0896]$} \\
\hline$\phi_{T}($ state $\mathrm{AF})$ & coeff. of lump-sum tax to debt & Normal & -0.01 & 0.01 & 0 & -0.0001 & {$[-0.0009,0.0007]$} \\
\hline$\rho_{R}($ state AM) & persistence of interest rate & Beta & 0.2 & 0.9 & 0.6689 & 0.6724 & {$[0.6587,0.6867]$} \\
\hline$\rho_{R}($ state PM $)$ & persistence of interest rate & Beta & 0.2 & 0.9 & 0.7772 & 0.7801 & {$[0.7685,0.7913]$} \\
\hline$\rho_{T}$ (state PF) & persistence of lump-sum tax & Beta & 0.2 & 0.9 & 0.5254 & 0.5311 & {$[0.5139,0.5597]$} \\
\hline$\rho_{T}($ state $\mathrm{AF})$ & persistence of lump-sum tax & Beta & 0.2 & 0.9 & 0.5043 & 0.4978 & {$[0.4825,0.5105]$} \\
\hline \multicolumn{8}{|c|}{ Economic parameters } \\
\hline$\alpha^{O}$ & capital share in oil production & Uniform & 0.1 & 0.3 & 0.1851 & 0.1848 & {$[0.1632,0.2031]$} \\
\hline$\chi^{O}$ & labour share in oil production & Uniform & 0.1 & 0.3 & 0.132 & 0.1178 & {$[0.1024,0.1329]$} \\
\hline$(1 / \beta-1) * 100$ & households discount rate & Uniform & 0.5 & 2 & 1.1118 & 1.1215 & {$[1.1032,1.1409]$} \\
\hline$\phi^{a}$ & sensitivity of risk premium to NFA & Gamma & 0.002 & 0.05 & 0.0793 & 0.0945 & {$[0.0833,0.108]$} \\
\hline$\lambda_{d}-1$ & intermediate goods markup & Uniform & 0.05 & 0.3 & 0.1727 & 0.1812 & {$[0.1674,0.1974]$} \\
\hline$\lambda_{w}-1$ & wage markup & Uniform & 0.01 & 0.1 & 0.0431 & 0.0412 & {$[0.0232,0.0576]$} \\
\hline$\sigma_{L}$ & inverse of Frisch elasticity & Uniform & 0.3 & 2 & 1.3799 & 1.3747 & {$[1.3518,1.3968]$} \\
\hline$\xi_{d}$ & price adjustment duration & Beta & 0.2 & 0.9 & 0.2879 & 0.2829 & {$[0.2608,0.3038]$} \\
\hline$\xi_{w}$ & wage adjustment duration & Beta & 0.2 & 0.9 & 0.9096 & 0.9106 & {$[0.8938,0.9339]$} \\
\hline$\kappa_{d}$ & price indexation & Beta & 0.2 & 0.9 & 0.3995 & 0.3999 & {$[0.3791,0.4234]$} \\
\hline$\kappa_{w}$ & wage indexation & Beta & 0.2 & 0.9 & 0.7069 & 0.7128 & {$[0.6952,0.7318]$} \\
\hline$\eta_{i}$ & price elasticity of investment demand & Gamma & 0.1 & 0.8 & 0.4161 & 0.4145 & {$[0.4003,0.4287]$} \\
\hline$\eta_{c}$ & price elasticity of consumption demand & Gamma & 0.1 & 0.8 & 1.5091 & 1.5084 & {$[1.4858,1.5256]$} \\
\hline$\eta_{f}$ & price elasticity of foreign demand & Gamma & 0.1 & 0.8 & 0.9713 & 0.9617 & {$[0.9386,0.981]$} \\
\hline$b$ & habit formation & Beta & 0.4 & 0.8 & 0.6064 & 0.5989 & {$[0.5667,0.6231]$} \\
\hline$\sigma_{a}^{N} O$ & utilization adjustment cost & Gamma & 0.5 & 2 & 0.3016 & 0.3009 & {$[0.2944,0.3077]$} \\
\hline$s_{N}^{\prime \prime} O$ & capital adjustment costs & Gamma & 2 & 8 & 4.8514 & 4.8604 & {$[4.8458,4.8736]$} \\
\hline$\sigma_{a}^{O}$ & utilization adjustment cost & Gamma & 0.5 & 2 & 1.1894 & 1.1943 & {$[1.1797,1.2112]$} \\
\hline$s_{O}^{\prime \prime}$ & capital adjustment costs & Gamma & 2 & 8 & 3.7611 & 3.7524 & {$[3.7362,3.7713]$} \\
\hline \multicolumn{8}{|l|}{ Shocks } \\
\hline$\rho_{y^{*}}$ & persistence of foreign demand & Beta & 0.2 & 0.9 & 0.5688 & 0.5639 & {$[0.5478,0.5819]$} \\
\hline$\rho_{R^{*}}$ & persistence of world interest rate & Beta & 0.2 & 0.9 & 0.9529 & 0.9398 & {$[0.9216,0.9531]$} \\
\hline$\rho_{O Y}$ & persistence of oil resourse & Beta & 0.2 & 0.9 & 0.3867 & 0.3841 & {$[0.3719,0.3973]$} \\
\hline$\rho_{O P}$ & persistence of oil prices & Beta & 0.2 & 0.9 & 0.8004 & 0.802 & {$[0.786,0.8171]$} \\
\hline$\rho_{\zeta_{c}}$ & persistence of consumption preference & Beta & 0.2 & 0.9 & 0.4124 & 0.414 & {$[0.3992,0.4286]$} \\
\hline$\rho_{g}$ & persistence of government consumption & Beta & 0.2 & 0.9 & 0.8547 & 0.8518 & {$[0.8365,0.8704]$} \\
\hline$\rho_{z}$ & persistence of technology & Beta & 0.2 & 0.9 & 0.8217 & 0.8233 & {$[0.8105,0.8379]$} \\
\hline$\rho_{\tilde{\xi} e}$ & persistence of risk premium & Beta & 0.2 & 0.9 & 0.8862 & 0.8806 & {$[0.8656,0.8938]$} \\
\hline$\sigma_{O P}$ & std. dev. of oil prices & Inv_Gamma & 0.001 & 0.5 & 0.1573 & 0.156 & {$[0.1452,0.1672]$} \\
\hline$\sigma_{O Y}$ & std. dev. of oil output & Inv_Gamma & 0.001 & 0.5 & 0.0999 & 0.0946 & {$[0.0862,0.1033]$} \\
\hline$\sigma_{\zeta_{c}}$ & std of consumption preference & Inv_Gamma & 0.001 & 0.5 & 0.0339 & 0.0316 & {$[0.0279,0.0357]$} \\
\hline$\sigma_{g}$ & std of government consumption & Inv_Gamma & 0.001 & 0.5 & 0.0069 & 0.0068 & {$[0.0061,0.0077]$} \\
\hline$\sigma_{\mathcal{E}_{r}}$ & std of monetary policy shock & Inv_Gamma & 0.001 & 0.5 & 0.0035 & 0.0035 & {$[0.003,0.0041]$} \\
\hline$\sigma_{z}$ & std of technology & Inv_Gamma & 0.001 & 0.5 & 0.0075 & 0.008 & {$[0.007,0.0092]$} \\
\hline$\sigma_{Y^{*}}$ & std. dev. of foreign demand & Inv_Gamma & 0.001 & 0.5 & 0.001 & 0.001 & {$[0.0008,0.0011]$} \\
\hline$\sigma_{R^{*}}$ & std. dev. of world interest rate & Inv_Gamma & 0.001 & 0.5 & 0.0023 & 0.0027 & {$[0.0009,0.0055]$} \\
\hline$\sigma_{\xi e}$ & std of risk premium & Inv_Gamma & 0.001 & 0.5 & 0.0056 & 0.0063 & {$[0.0054,0.0074]$} \\
\hline
\end{tabular}


We let fiscal policy rule coefficient $\phi_{T}$ follow a gamma distribution with 0.05 to 0.25 covering the $90 \%$ probability interval when under the PF regime, which requires the fiscal policy to passively adjust to accommodate debt accumulation. In contrast, under the AF regime, fiscal policy is unable to aggressively react to the outstanding debt level, hence we let $\phi_{T}$ follow a normal distribution with -0.01 to 0.01 covering the 90 percent probability interval. Policy persistence parameters $\rho_{R}$ and $\rho_{T}$ follow a beta distribution with a $90 \%$ probability range between 0.2 and 0.9 . The above prior ranges for policy parameters cover the value used in many macroeconomic studies. ${ }^{1}$ The off-diagonal terms of each transition matrix $p^{12}, p^{21}, q^{12}$, and $q^{21}$ follow a beta distribution with 0.01 to 0.2 covering the $90 \%$ probability interval. This range for transition probabilities covers the values estimated by Davig and Leeper (2011), Bianchi (2012), and Bianchi and Ilut (2017).

Next, we discuss the prior distributions for other economic parameters. The priors for these parameters are invariant across regimes and are relatively loose compared to previous studies. Capital and the labor share parameters in the oil production function follow a uniform distribution with a $90 \%$ probability range between 0.1 and 0.3 . The transform of the households discount rate, $100(1 / \beta-1)$, follows a uniform distribution with quantiles 0.5 and 2 covering the $90 \%$ probability interval. We let the transform of the intermediate goods markup, $\lambda_{d}-1$, follow a uniform distribution with 0.05 to 0.3 covering the $90 \%$ probability interval. The transform of the wage markup, $\lambda_{w}-1$, follows a uniform distribution with the $90 \%$ probability range given by 0.01 to 0.1. The Frisch elasticity of labor supply follows a uniform distribution with the $90 \%$ probability range given by $[0.3,2]$. The sensitivity of the risk premium to NFA follows a gamma distribution with a $90 \%$ probability range between 0.002 and 0.05 .

The price and wage adjustment duration parameters, $\xi_{d}$ and $\xi_{w}$, follow a beta distribution with quantiles 0.2 and 0.9 covering the $90 \%$ probability interval. We let the price and wage indexation $\kappa_{d}$ and $\kappa_{w}$ follow a beta distribution such that the quantiles 0.2 and 0.9 cover $90 \%$ of the probability interval. The price elasticity of foreign demand, domestic investment, and consumption demand follow a gamma distribution with a $90 \%$ probability range given by $[0.1,0.8]$. The utilization adjustment cost $\sigma_{a}$ follows a gamma distribution with a $5 \%$ to $95 \%$ probability range given by $[0.5,2]$. We let the capital adjustment cost $s^{\prime \prime}$ follow a gamma distribution with quantiles 2 and 8 covering the $90 \%$ probability interval. The consumption habit follows a beta distribution with a $90 \%$ probability range between 0.4 and 0.8 .

Finally, the priors for the persistence coefficients of the exogenous shock process

\footnotetext{
${ }^{1}$ See for example Leeper et al. (2017).
} 
follow a beta distribution with a $90 \%$ probability range between 0.2 and 0.9 . The standard deviations of each of the nine shocks follow an inverse gamma distribution with the $90 \%$ probability range given by $[0.001,0.5]$.

4.4 Posterior Table 3 reports the mode, the mean, and the 5 and 95 percentiles of the posterior distribution of the estimated parameters. The estimation results show tighter posterior ranges for policy coefficients relative to the prior ranges, which implies the data are informative to identify those parameters. The posteriors for transition probabilities suggest that the four regimes are highly persistent. The probability of moving from the AM regime to the PM regime is lower than the probability of moving from the PM to the AM regime. For the fiscal policy, the probability of moving from the AF regime to the PF regime is lower than the probability of moving from the PF to the AF regime.

As for the other structural parameters reported in middle panel of table 3, it is worth pointing out that the estimation results are comparable to the results found in previous studies. The estimated results for shock processes are reported in the lower panel of table 3. The AR(1) coefficients for all shocks are sizable. Although the prior distributions for all the shock variances are the same, the posterior estimates are very dispersed. The oil price and oil output shock has the largest variance whereas the foreign demand shock had the smallest variance.

One of the most important criterion for judging the validity of identification as used by Smets and Wouters (2007) and Christiano et al. (2014) is that the standard deviation of the posterior distribution should be less than the standard deviation of the prior distribution. Overall, it appears that our data are quite informative on the estimated parameters, as indicated by the narrow range of the $90 \%$ probability interval of the posterior distribution relative to the prior distribution.

\section{EMPIRICAL RESULTS}

We present the results obtained from estimating the Markov-switching small open economy DSGE model in this section. We first report model fit, and then examine the theoretical variance decomposition of structural shocks, emphasizing the contribution of oil price shocks. We also report the regime probabilities and the regime-specific impulse responses to emphasize how the monetary and fiscal policy mix influences the dynamics of key macroeconomic variables, especially inflation and exchange rate. 

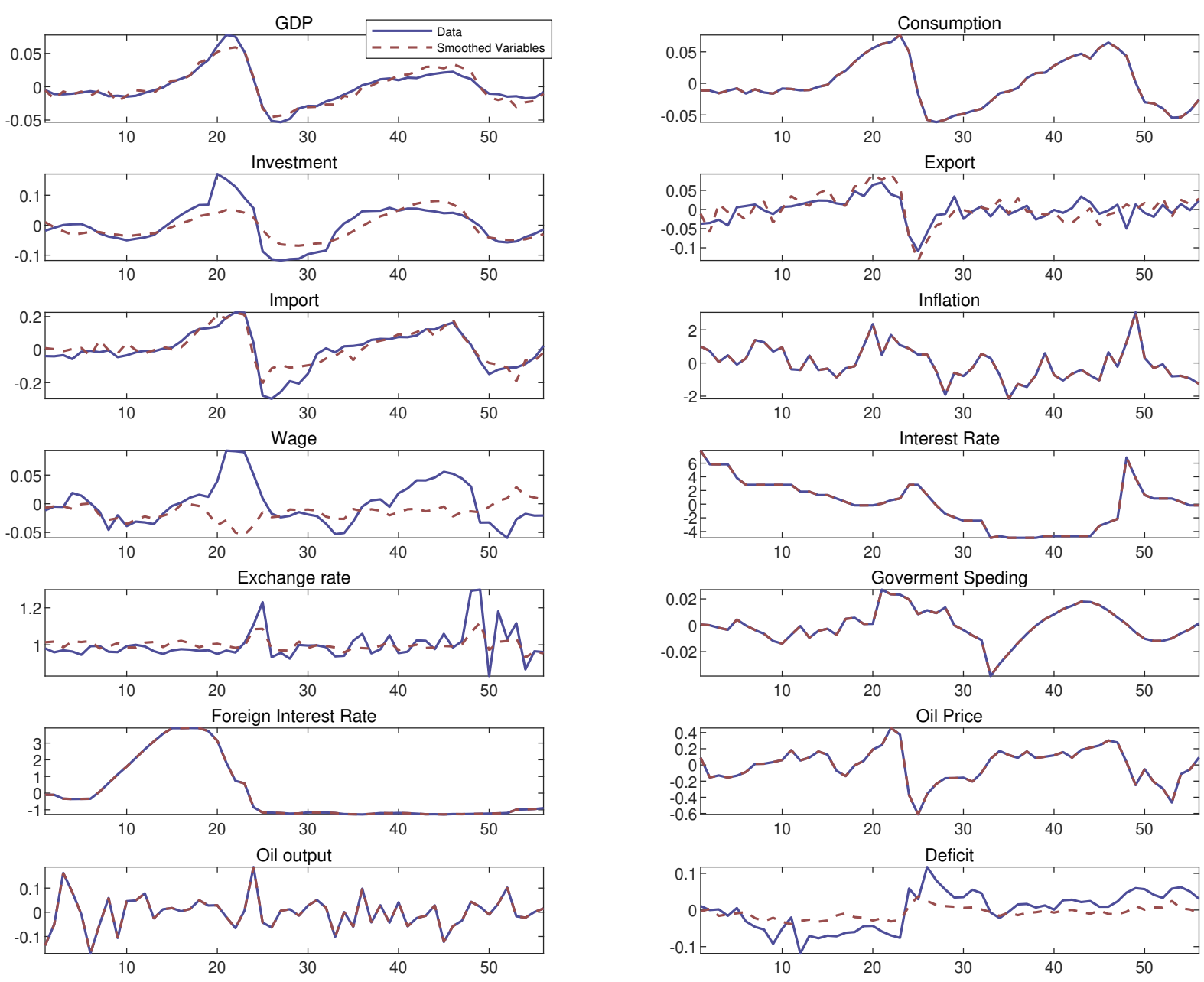

Figure 3: Model-Smoothed Values (red dashed line) vs. Data (blue solid line)

5.1 MODEL FIT Figure 3 plots the model-smoothed values for macroeconomic variables along with their data counterparts over our sample period. The model-smoothed values are computed using the posterior mode. The blue solid line presents the data, whereas the red dashed line presents the model-smoothed values. We can see that the red dashed line tracks the blue solid line relatively well, especially the inflation rate and the exchange rate. The model produces a good fit for the oil price and oil output, which are crucial for oil-exporting countries. The model is also able to explain the business cycle dynamics for standard key macroeconomic variables, such as output and consumption, but produces less volatile investment dynamics relative to the data. Overall, the in-sample fit of the model appears to be satisfactory.

Next, we compute the first and second moments generated by the model and compare them with their data counterparts. The first moment is given by the steady state of the model, and we calculate the second moment by model simulation. Table 4 presents 
Table 4: First Moments: Model versus Data

\begin{tabular}{llcc}
\hline \hline Steady State & Description & Model & Data \\
\hline$I / G D P$ & investment-to-GDP ratio & 0.23 & 0.20 \\
$M / G D P$ & import-to-GDP ratio & 0.22 & 0.22 \\
$E X / G D P$ & export-to-GDP ratio & 0.22 & 0.29 \\
$C / G D P$ & consumption-to-GDP ratio & 0.57 & 0.51 \\
$P^{O} Y^{O} / G D P$ & oil-output-to-GDP ratio & 0.10 & 0.10 \\
$G / G D P$ & government-spending-to-GDP ratio & 0.19 & 0.19 \\
$\tau^{O} P^{O} Y^{O} /\left(\tau^{O} P^{O} Y^{O}+T R\right)$ & government oil income share & 0.41 & 0.45 \\
\hline
\end{tabular}

Note: All sample averages are computed over the period 2003Q1-2016Q4, except oil income share, which is computed over 2006Q3-2016:Q4.

our results. We can see that the consumption-to-GDP ratio is higher in the model than that in the data, and the export-to-GDP ratio in the model is lower than that in the data. Other than the above two ratios, the other steady-state ratios of the model are close to the data counterparts.

Table 5: Second Business Cycle Moments: Data vs. Model

\begin{tabular}{|c|c|c|c|c|}
\hline Variable & & Standard deviation (\%) & $\begin{array}{c}\text { Standard deviation } \\
\text { relative to GDP }\end{array}$ & $\begin{array}{c}\text { Correlations with } \\
\text { GDP }\end{array}$ \\
\hline \multirow[t]{2}{*}{ GDP } & Model & 3.16 & 1 & 1 \\
\hline & Data & 2.67 & 1 & 1 \\
\hline \multirow[t]{2}{*}{ Consumption } & Model & 2.14 & 0.68 & 0.87 \\
\hline & Data & 3.78 & 1.42 & 0.89 \\
\hline \multirow[t]{2}{*}{ Investment } & Model & 8.17 & 2.58 & 0.88 \\
\hline & Data & 6.50 & 2.44 & 0.94 \\
\hline \multirow[t]{2}{*}{ Exchange Rate } & Model & 2.60 & 0.82 & 0.38 \\
\hline & Data & 8.49 & 3.18 & 0.02 \\
\hline \multirow[t]{2}{*}{ Inflation } & Model & 1.32 & 0.42 & 0.35 \\
\hline & Data & 1.00 & 0.37 & 0.31 \\
\hline \multirow[t]{2}{*}{ Oil Price } & Model & 22.44 & 7.10 & 0.82 \\
\hline & Data & 20.83 & 7.80 & 0.65 \\
\hline
\end{tabular}

Note: The data-implied moments are calculated after HP-filtering in logs except for the inflation, exchange rate, and interest rate, which are in levels. The model-implied moments are calculated using simulation variables.

We report the second moments in table 5 . We can see that the model is able to 
generate a procyclical inflation and oil price that is consistent with the data. The model is also able to generate a more volatile investment and oil price relative to output and less volatile inflation relative to output.

Table 6 presents the model fit measured by the posterior log-likelihood. A higher log marginal density measure indicates a better fit. By the criterion of posterior loglikelihood, the data strongly prefer the benchmark regime switching specification. This finding supports that the notion that monetary policy and fiscal policy regime switching is crucial when examining the macroeconomic dynamics for Russia.

Table 6: Log Marginal Density

\begin{tabular}{lc}
\hline \hline Model & Log marginal density \\
\hline Fixed coefficient & 726.4 \\
Regime switching in policy rule coefficients & 982.3 \\
\hline $\begin{array}{l}\text { Note: The posterior log-likelihood uses the average of Geweke's (1999) modified harmonic mean estimator. For the fixed coeffi- } \\
\text { cient model, we chose the AM/PF specification. }\end{array}$
\end{tabular}

Table 7: Variance Decomposition: Contribution of Oil Price Shocks

\begin{tabular}{llcc}
\hline \hline & & Regime & \\
\cline { 2 - 4 } Variable & Ergodic & PM/AF & AM/PF \\
\hline Output & 61.58 & 89.24 & 56.91 \\
Consumption & 30.88 & 90.17 & 31.11 \\
Labor & 21.08 & 66.03 & 38.31 \\
Export & 72.95 & 90.91 & 63.32 \\
Wage & 11.67 & 39.32 & 21.1 \\
Interest rate & 32.39 & 77.79 & 33.96 \\
Exchange rate & 46.86 & 77.18 & 35.68 \\
Inflation & 21.12 & 63.95 & 22.41 \\
Real exchange rate & 73.11 & 90.97 & 63.46 \\
Deficit & 90.62 & 88.97 & 89.99 \\
\hline
\end{tabular}

Note: The data-implied moments are calculated after HP-filtering in logs except for the inflation, exchange rate, and interest rate, which are in levels. The model-implied moments are calculated using simulation variables.

5.2 VARIANCE DECOMPOSITION In order to gauge the importance of oil price shocks under various policy regimes, we conduct variance decomposition for key macroeconomic variables, and report the results in table 7 . In the ergodic case, the variance 
decomposition is computed when regime switching is allowed. The other two cases report variance decomposition under fixed regimes. We can see that overall, oil price shocks account for a significant fraction of variation for most macroeconomic variables, especially for the nominal and real exchange rates, inflation, and government deficit. More importantly, the contribution of the oil price shocks is greater when in the $\mathrm{PM} / \mathrm{AF}$ regime than when in the $\mathrm{AM} / \mathrm{PF}$ regime, suggesting the impact of oil price shocks is asymmetric across policy regimes.

Hence, our results imply that when analyzing the effects of oil price shocks for oil-exporting countries, we need to take possible policy regime switching into consideration. Otherwise we may underestimate the impact of oil price variations on macroeconomic stability, especially for inflation and exchange rates.
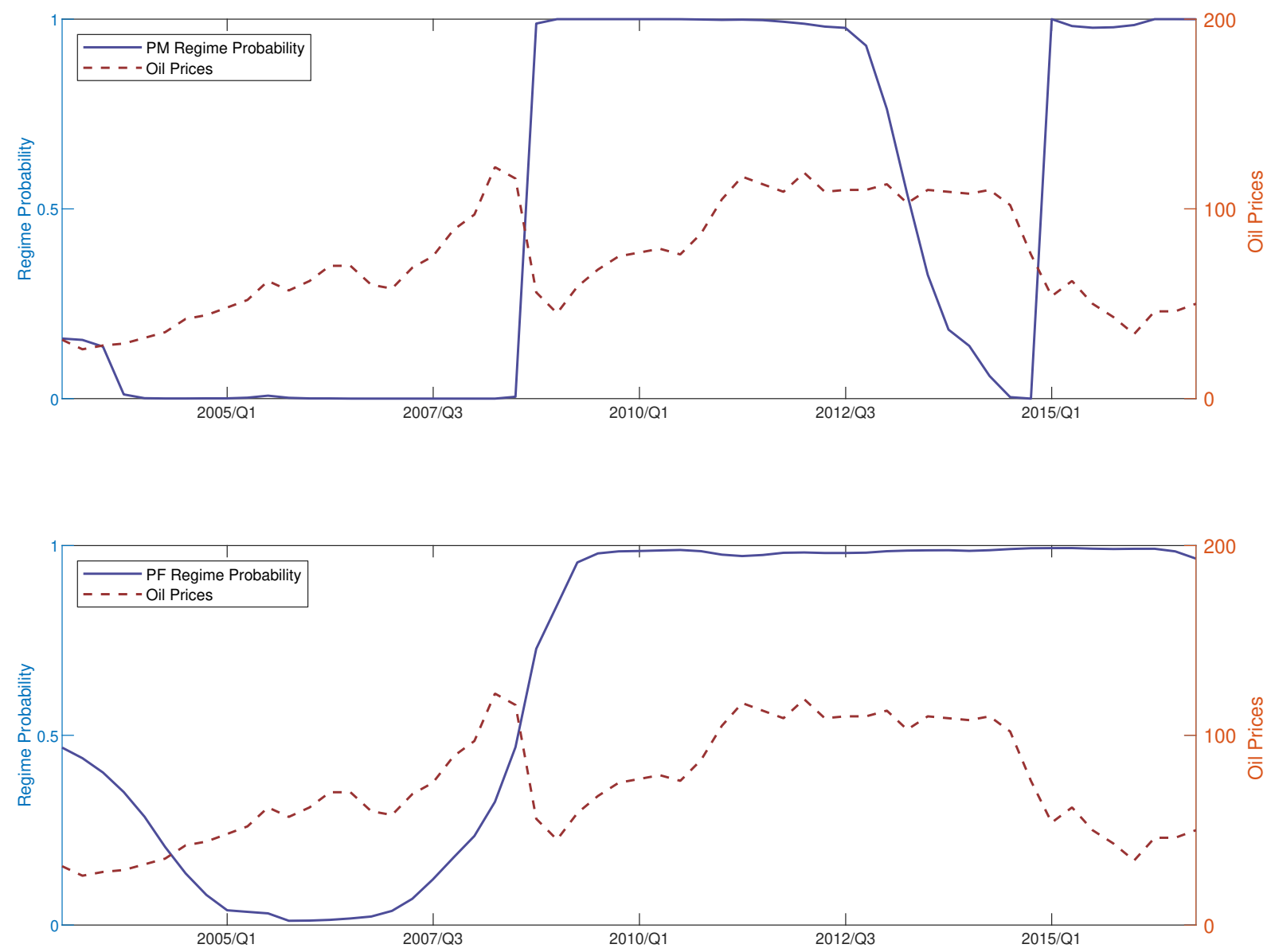

Figure 4: Smoothed State Probabilities and Oil Price

5.3 Smoothed State Probabilities We plot the smoothed regime probabilities, together with oil price in figure 4 . The blue solid line shows the probability of policy regime, and the red dashed line shows the oil price. The top panel plots the probability 
of being in the PM regime, and the bottom panel shows the probability of being in the AF regime.

This figure suggests that although the AM regime turns out to be prevalent for most of the sample periods, there has been policy regime switching in Russia over the sample periods. Moreover, the period of regime switching is highly correlated with the drop in oil price. In particular, we can see that when oil prices fell significantly during the 2008 financial crisis and the last quarter of 2014 to the last quarter of 2015 period, there was a high probability (nearly 1 ) of the PM regime. The fiscal policy switched to the AF regime since the 2008 financial crisis and did not return to the PF regime thereafter.

Therefore, the above results support the argument that the fall of oil price is strongly related to the switching of monetary and fiscal policy regimes for Russia, which is also consistent with the narrative evidence.

5.4 Regime-Dependent Transmission Mechanisms To examine the transmission mechanisms of oil price shocks under different policy regimes, we plot the impulse responses of macroeconomic variables in figure 5 when the small open economy is subject to a negative oil price shock, conditional on AM/PF and PM/AF regimes. Since the AM/PF regime resembles the monetary and fiscal policy configuration during normal times, the impulse response functions in this regime are not surprising. Figure 5 shows that output, investment, and consumption fall, but households work more because of the wealth effect. Government debt burden rises and the lump-sum tax also rises. In the PM/AF regime, as oil revenue drops and tax does not rise sufficiently, the present value of real fiscal resources are not able to support the outstanding government debt. This fiscal stress then requires the price level to rise to inflate away part of the nominal government debt and exchange rates to depreciate to revalue the government expenditures against dollars. We can see from figure 5 that the impulse responses for inflation and the exchange rate are qualitatively the same as those in the $\mathrm{AM} / \mathrm{PF}$ regime. However, the magnitude of the responses differs substantially. The inflation and the exchange rate responses are roughly three times larger. On the other hand, the responses of real variables are milder under the PM/AF regime. This is because the rise of the nominal interest rate is less than the rise of inflation, which produces a fall of the real interest rate. This in turn stimulates the investment and mitigates the contractionary effect of the negative oil price shock.

We now turn to discuss the role of nominal frictions in this model. We report the results in appendix B. In particular, figure 7 shows the macroeconomic dynamics with 

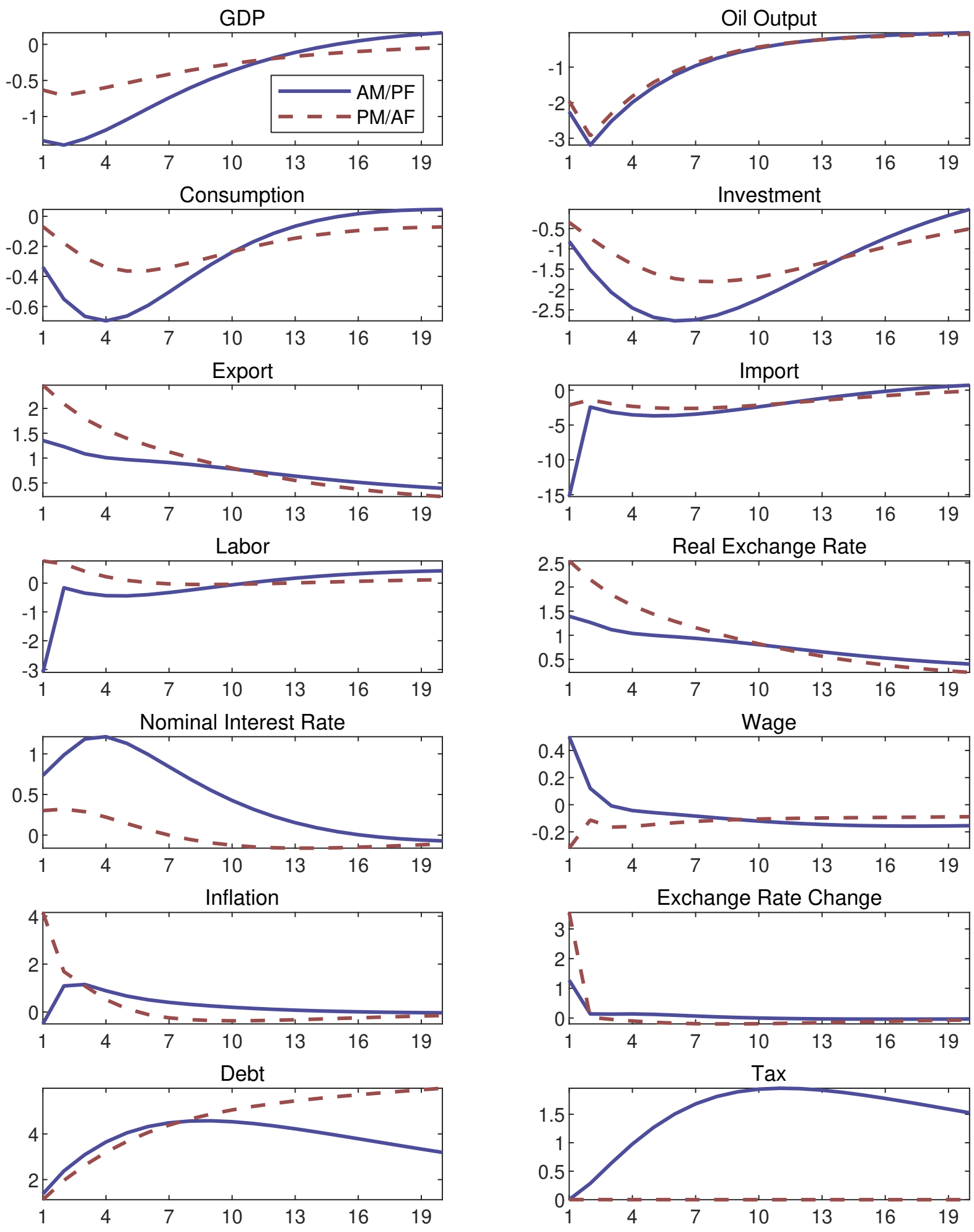

Figure 5: Macroeconomic Dynamics in Response to an Oil Price Fall 
different degrees of price stickiness in response to a unfavorable oil price shock under the PM/AF regime. We can see that when price is more flexible, the rise of inflation is higher. The export and the consumption increase more, hence the output decreases less. Figure 8 shows the impulse responses with different degrees of wage stickiness. When nominal wage is more flexible, inflation increases more and wage rate decreases more. The investment and output decrease less.

\section{COUnTERfactual AnALysis}

In this section, we conduct two counterfactual policy experiments to illustrate how the policy regime switches affect the observed macroeconomic dynamics.
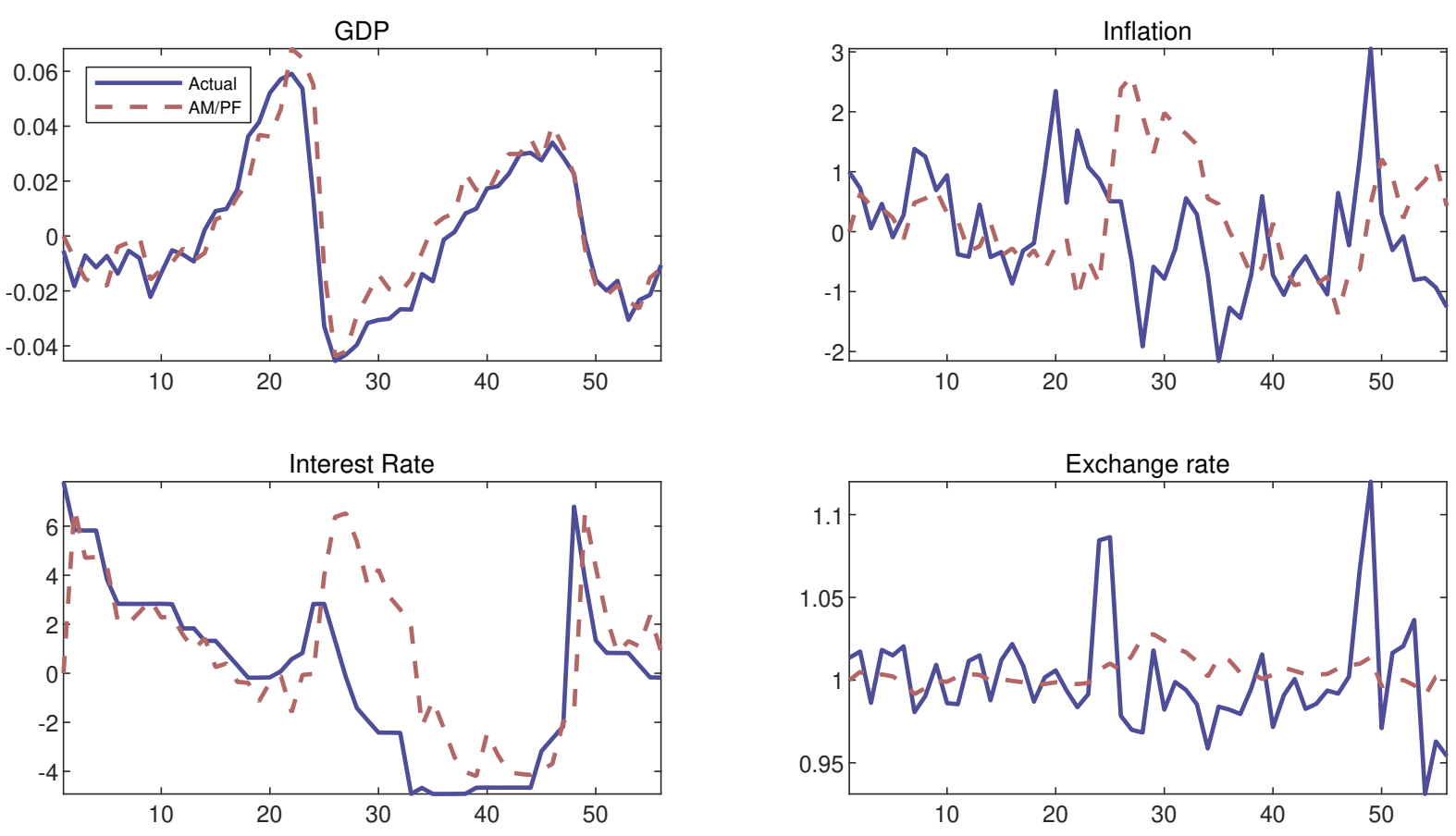

Figure 6: Counterfactual Historical Simulations

6.1 Counterfactual Experiment: In-Sample Performance The first counterfactual analysis explores how the key macroeconomics variables would have been different if the policy coefficients did not switch over the sample period. Figure 6 reports the historical time series of GDP, inflation, nominal interest rate, and exchange rate under the benchmark regime switching case, which is marked with a solid blue line, along with the time series generated under the AM/PF regime, which is marked with a red dashed line. This figure clearly shows that the model fails to produce the observed variations of inflation and the exchange rate in the past. In particular when 
inflation climbs high, and exchange rate depreciates significantly during the 2008 financial crisis and the periods from 2014Q4 to 2016Q2.

Table 8: Counterfactual Second Moments: Oil Price and Exchange Rate

\begin{tabular}{cccc}
\hline \hline Variable & Baseline & AM/PF & PM/AF \\
\hline $\operatorname{Corr}\left(P^{O}, s\right)$ & -0.44 & -0.11 & -0.46 \\
$\operatorname{Std}(s)$ & 3.21 & 0.78 & 3.23 \\
\hline
\end{tabular}

Note: The baseline case allows regime switching.

\subsection{Counterfactual Experiment: Second Moments Our second counterfac-} tual exercise is to compare the second moments using counterfactual simulated time series under different policy regimes. Table 8 reports the correlation between oil prices and the exchange rate simulated under the benchmark regime switching model, the $\mathrm{AM} / \mathrm{PF}$ policy regime, the PM/AF policy regime, and the data counterpart. We can see that this correlation is much stronger conditional on the PM/AF regime relative to that conditional on the AM/PF regime. This helps to explain the asymmetric correlation observed in the data across different periods. In addition, the standard deviation of the exchange rate is higher under the $\mathrm{PM} / \mathrm{AF}$ regime relative to that under the $\mathrm{AM} / \mathrm{PF}$ regime, which is consistent with the data observed under different exchange rate arrangements.

Overall, the counterfactual analysis shows the importance of allowing monetary and fiscal policy regime switching to interpret the data from two aspects: the time series based on the historical sequence of shocks and unconditional moments obtained by stochastic simulations.

\section{RobUstness CHECK}

In this section, we conduct a couple of robustness checks for the main results. First, we check the sensitivity of the estimation results to different prior distributions. Following Smets and Wouters (2007), we broaden the $90 \%$ probability intervals of the prior distributions by $50 \%$ for all the parameters. The estimation results do not change much.

Second, admittedly the Russian economy is in a state of transition, and there maybe uncertainty about which long-run equilibrium the economy is converging to. To address this concern, we experiment with different HP-filter parameter values to remove 
the long-run trend, and find the results do not change much. In addition, we reestimate the model using the data of Algeria, which is also an oil-exporting country under a managed floating exchange rate system. We report the estimated regime probabilities in appendix $C$. We can see that the data implied regime switching probabilities are similar to those of Russia.

\section{CONCLUSION}

In this paper, we documented how oil price variations have time-varying asymmetric impacts on exchange rates for some oil-exporting countries. The correlation between oil prices and exchange rates is strongly negative during periods of significant oil price drop, but it becomes weak, or even positive, during other periods. To interpret the data pattern, we developed a Markov-switching small open economy New Keynesian model with tax income from oil production and estimated the model based on Russia, which is a prototype oil-exporting country. In particular, we allowed monetary and fiscal policy rules to fluctuate across different regimes in order to quantitatively assess the importance of monetary and fiscal policy interactions in producing the time-varying asymmetric correlation between exchange rates and oil prices.

We found evidence of policy regime switching over the sample period. Our estimation result shows that the sharp falling of oil prices generates fiscal stress that keeps the fiscal policy from accommodating public debt. Monetary policy in turn has to adjust, either currently or in the future, to passively tolerate higher inflation and currency depreciation in order to restore the backing of government debt. During other periods of time, monetary policy actively controls inflation and the exchange rate, while fiscal policy adjusts to accommodate government debt accumulation. This policy combination effectively isolates the oil price variations to the exchange rate changes. We provided narrative evidence that supports the policy regime switches inferred from the model. Moreover, our counterfactual policy experiments show that conditional on the policy regime configuration during normal time, the model fails to produce the observed strong negative correlation between exchange rates and oil prices.

Moreover, impulse responses from the model show that the transmission channels of oil price shocks vary significantly across different policy combinations. Therefore, business cycle analysis conditional on a fixed monetary and fiscal policy combination is likely to misinterpret the data for oil-exporting countries, in particular the ones under a managed floating exchange rate arrangement. 


\section{REFERENCES}

Baele, L., G. Bekaert, S. Cho, K. Inghelbrecht, and A. Moreno (2015). Macroeconomic regimes. Journal of Monetary Economics 70, 51-71.

Berg, A., R. Portillo, S.-C. S. Yang, and L.-F. Zanna (2013). Public investment in resource-abundant developing countries. IMF Economic Review 61(1), 92-129.

Bhattarai, S., J. W. Lee, and W. Y. Park (2016). Policy regimes, policy shifts, and us business cycles. Review of Economics and Statistics 98(5), 968-983.

Bianchi, F. (2012). Regime switches, agents' beliefs, and post-world war ii us macroeconomic dynamics. Review of Economic studies 80(2), 463-490.

Bianchi, F. and C. Ilut (2017). Monetary/fiscal policy mix and agents' beliefs. Review of economic Dynamics 26, 113-139.

Bjørnland, H. C., V. H. Larsen, and J. Maih (2018). Oil and macroeconomic (in) stability. American Economic Journal: Macroeconomics 10(4), 128-51.

Broda, C. (2004). Terms of trade and exchange rate regimes in developing countries. Journal of International economics 63(1), 31-58.

Burnside, C. A., M. S. Eichenbaum, and S. Rebelo (2001). Prospective deficits and the asian currency crisis. Journal of Political Economy 109(6), 1155-1197.

Calvo, G. A. (1983). Staggered prices in a utility-maximizing framework. Journal of monetary Economics 12(3), 383-398.

Chang, C., Z. Liu, and M. M. Spiegel (2015). Capital controls and optimal chinese monetary policy. Journal of Monetary Economics 74, 1-15.

Christiano, L. J., M. Eichenbaum, and C. L. Evans (2005). Nominal rigidities and the dynamic effects of a shock to monetary policy. Journal of political Economy 113(1), $1-45$.

Christiano, L. J., R. Motto, and M. Rostagno (2014). Risk shocks. The American Economic Review 104(1), 27-65.

Cochrane, J. H. (2001). Long-term debt and optimal policy in the fiscal theory of the price level. Econometrica 69(1), 69-116. 
Corsetti, G. and B. Maćkowiak (2006). Fiscal imbalances and the dynamics of currency crises. European Economic Review 50(5), 1317-1338.

Daniel, B. C. (2001). A fiscal theory of currency crises. International Economic Review 42(4), 969-988.

Davig, T. and E. M. Leeper (2011). Monetaryfiscal policy interactions and fiscal stimulus. European Economic Review 55(2), 211-227.

Devereux, M. B., P. R. Lane, and J. Xu (2006). Exchange rates and monetary policy in emerging market economies. The Economic Journal 116(511), 478-506.

Economist (2015). Pegs under pressure. Economist.

Edwards, S. and E. L. Yeyati (2005). Flexible exchange rates as shock absorbers. European Economic Review 49(8), 2079-2105.

Erceg, C. J., D. W. Henderson, and A. T. Levin (2000). Optimal monetary policy with staggered wage and price contracts. Journal of monetary Economics 46(2), 281-313.

García-Cicco, J. and E. Kawamura (2015). Dealing with the dutch disease: Fiscal rules and macro-prudential policies. Journal of International Money and Finance 55, 205-239.

Garcia-Cicco, J., R. Pancrazi, and M. Uribe (2010). Real business cycles in emerging countries? American Economic Review 100(5), 2510-31.

Hou, K., D. C. Mountain, and T. Wu (2016). Oil price shocks and their transmission mechanism in an oil-exporting economy: A var analysis informed by a dsge model. Journal of International Money and Finance 68, 21-49.

Kliem, M., A. Kriwoluzky, and S. Sarferaz (2016). On the low-frequency relationship between public deficits and inflation. Journal of applied econometrics 31(3), 566-583.

Krugman, P. (1979). A model of balance-of-payments crises. Journal of money, credit and banking 11(3), 311-325.

Leeper, E. M. (1991). Equilibria under active and passive monetary and fiscal policies. Journal of monetary Economics 27(1), 129-147.

Leeper, E. M., N. Traum, and T. B. Walker (2017). Clearing up the fiscal multiplier morass. American Economic Review 107(8), 2409-2454. 
Liu, Z., D. F. Waggoner, and T. Zha (2011). Sources of macroeconomic fluctuations: A regime-switching dsge approach. Quantitative Economics 2(2), 251-301.

Maih, J. (2015). Efficient perturbation methods for solving regime-switching dsge models.

Medina, J. P., C. Soto, et al. (2005). Oil shocks and monetary policy in an estimated dsge model for a small open economy. Documento de Trabajo 353.

Pieschacón, A. (2012). The value of fiscal discipline for oil-exporting countries. Journal of Monetary Economics 59(3), 250-268.

Schmitt-Grohé, S. and M. Uribe (2003). Closing small open economy models. Journal of international Economics 61(1), 163-185.

Sims, C. A. and T. Zha (2006). Were there regime switches in us monetary policy? American Economic Review 96(1), 54-81.

Smets, F. and R. Wouters (2007). Shocks and frictions in us business cycles: A bayesian dsge approach. The American Economic Review 97(3), 586-606.

Woodford, M. (1996). Control of the public debt: A requirement for price stability? Technical report, National Bureau of Economic Research. 


\section{Appendices}

\section{A DATA DESCRIPTIONS}

In this section, we list all the data we used for estimation and their sources.

Nominal interest rate: Central Bank Rates for the Russian Federation, Percent, Quarterly, Not Seasonally Adjusted. Data source: Federal Reserve Economic Data.

Oil price: Global price of Brent Crude, U.S. Dollars per Barrell, Quarterly, Not Seasonally Adjusted. Data source: Federal Reserve Economic Data.

Import: Imports of Goods and Services for the Russian Federation (by Expenditure in Constant Prices), Chained 2000 National Currency Units, Quarterly, Seasonally Adjusted. Data source: Federal Reserve Economic Data.

Exports: Exports of Goods and Services for the Russian Federation (by Expenditure in Constant Prices), Chained 2000 National Currency Units, Quarterly, Seasonally Adjusted. Data source: Federal Reserve Economic Data.

GDP: Total Gross Domestic Product for the Russian Federation (by Expenditure in Constant Prices), Chained 2000 National Currency Units, Quarterly, Seasonally Adjusted. Data source: Federal Reserve Economic Data.

Government Spending: Government Final Consumption Expenditure for the Russian Federation (by Expenditure in Constant Prices), Chained 2000 National Currency Units, Quarterly, Seasonally Adjusted. Data source: Federal Reserve Economic Data.

Consumption: Private Final Consumption Expenditure for the Russian Federation (by Expenditure in Constant Prices), National Currency, Quarterly, Seasonally Adjusted. Data source: Federal Reserve Economic Data.

Inflation: Consumer Price Index, Total All Items for the Russian Federation, Growth Rate Previous Period, Quarterly, Not Seasonally Adjusted. Data source: Federal Reserve Economic Data.

Investment: Gross Fixed Capital Formation for the Russian Federation (by Expenditure in Constant Prices), Chained 2000 National Currency Units, Quarterly, Seasonally Adjusted. Data source: Federal Reserve Economic Data.

Exchange Rate: Average of Daily Rates for the Russian Federation, National Currency Units per US Dollar, Quarterly, Not Seasonally Adjusted. Data source: Federal Reserve Economic Data.

Foreign interest rate: Effective Federal Funds Rate, Percent, Monthly, Not Seasonally Adjusted. Data source: Federal Reserve Economic Data.

Wage: Real Wage Index, Quarterly, Not Seasonally Adjusted. Data source: CEIC 
Database.

Oil Output: Export of petroleum products, crude oil, million dollars. Data source: CEIC Database. Divided by oil price to obtain oil production.

Government Deficit: Government spending minus government revenue, billion Russian rubles. Data source: CEIC Database. 


\section{B COMPARATIVE DYNAMICS}
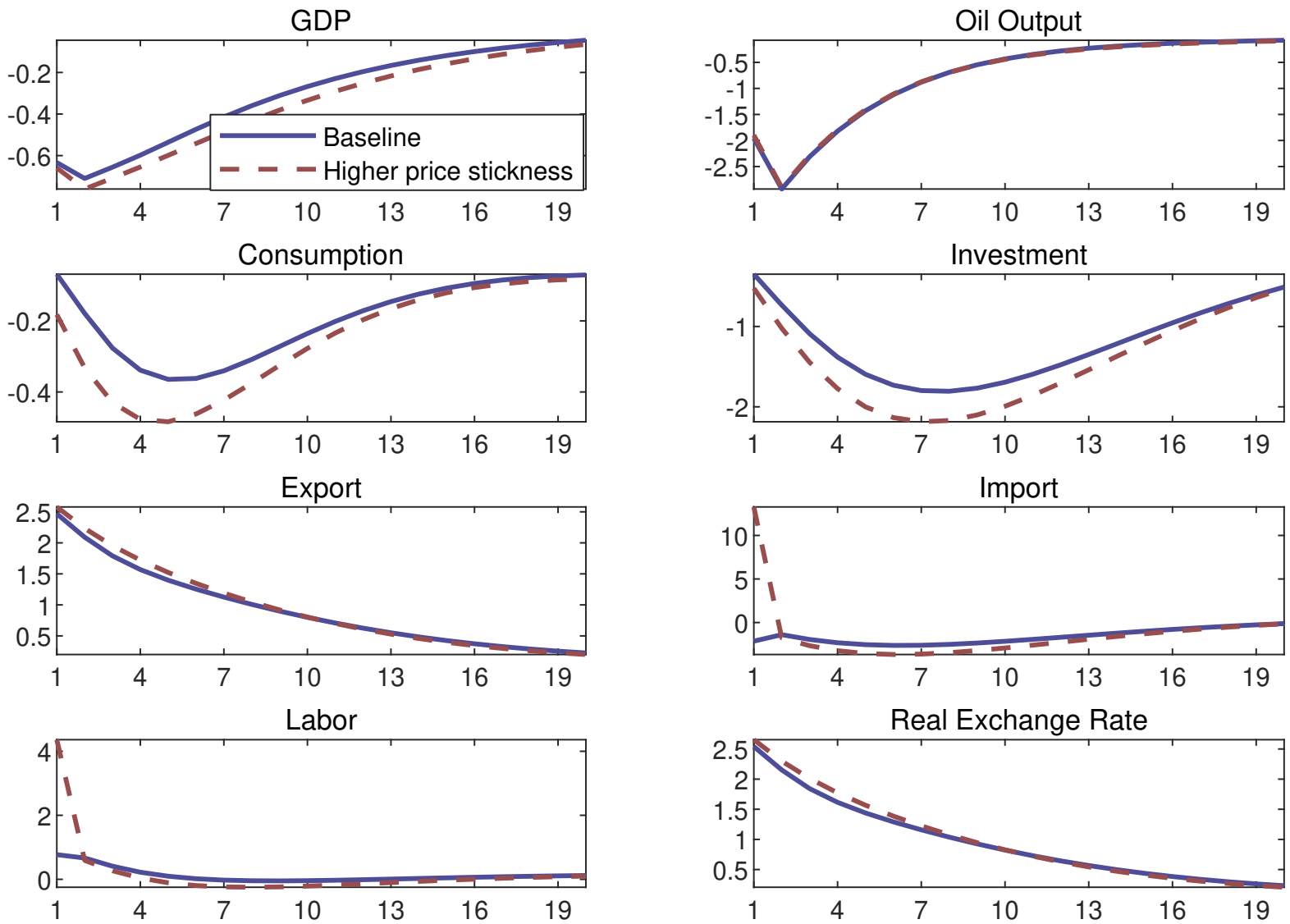

Real Exchange Rate
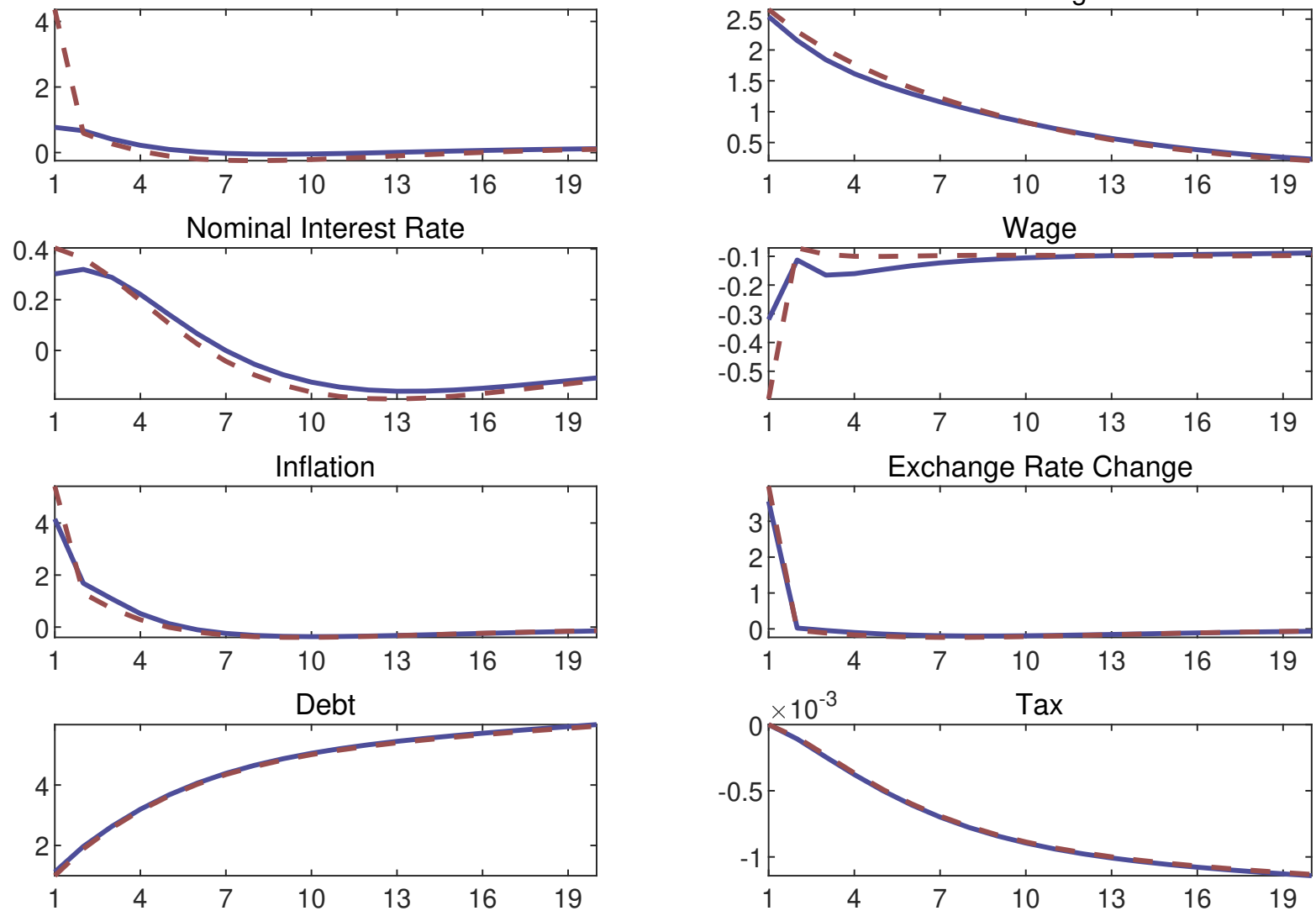

Figure 7: Macroeconomic Dynamics with Different Degrees of Price Stickiness 
GDP

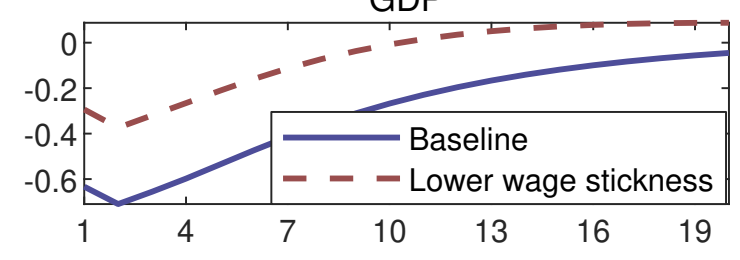

Consumption

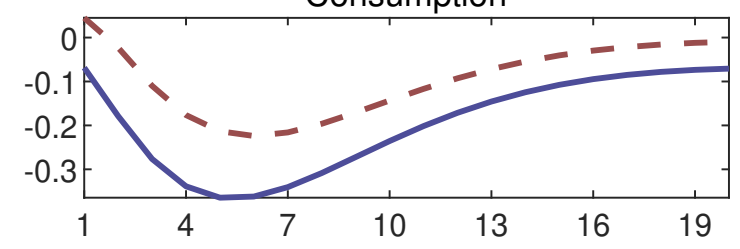

Export
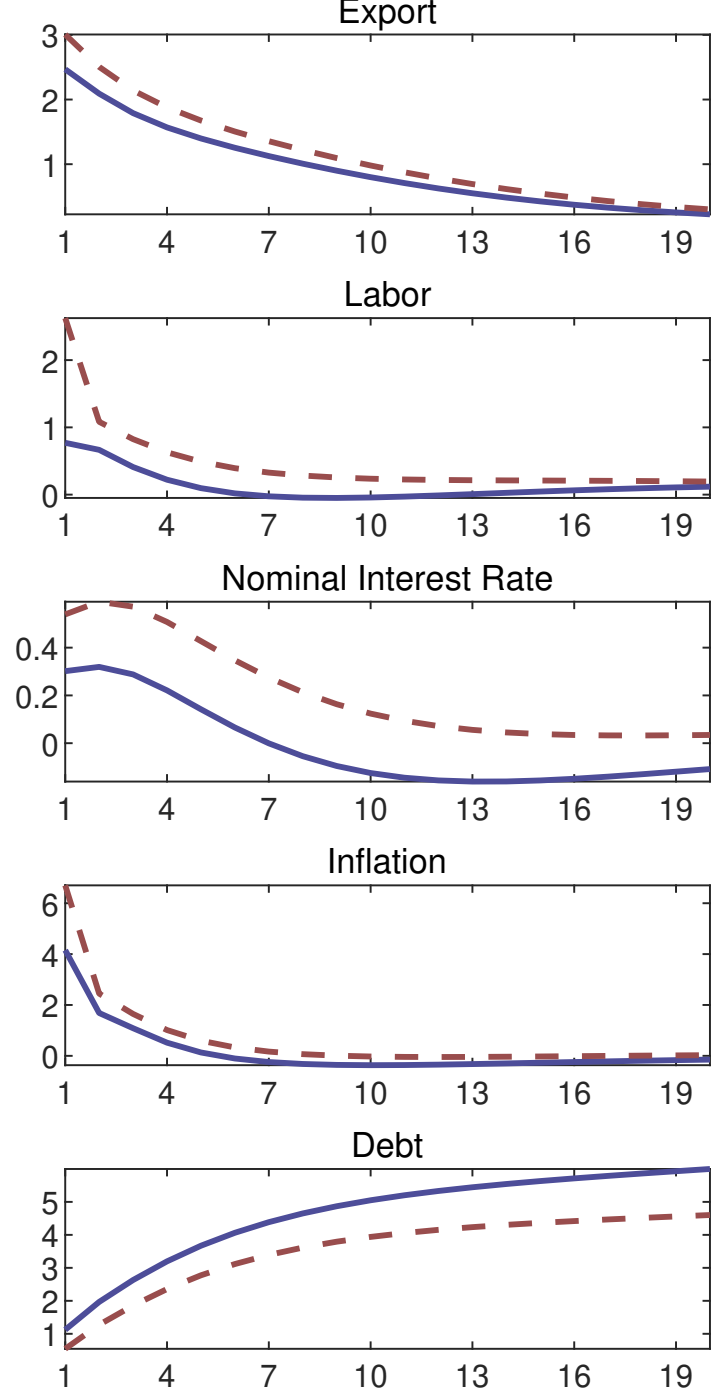
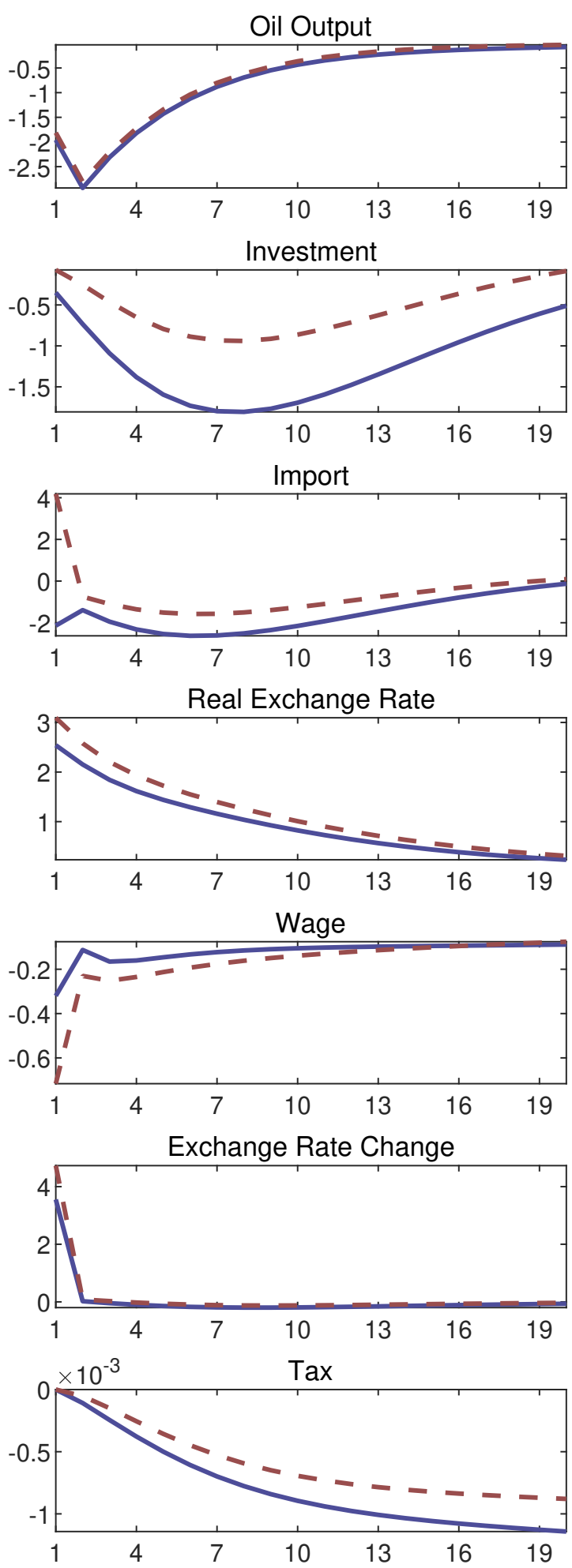

Figure 8: Macroeconomic Dynamics with Different Degrees of Wage Stickiness 


\section{Robustness Check: The Case of Algeria}
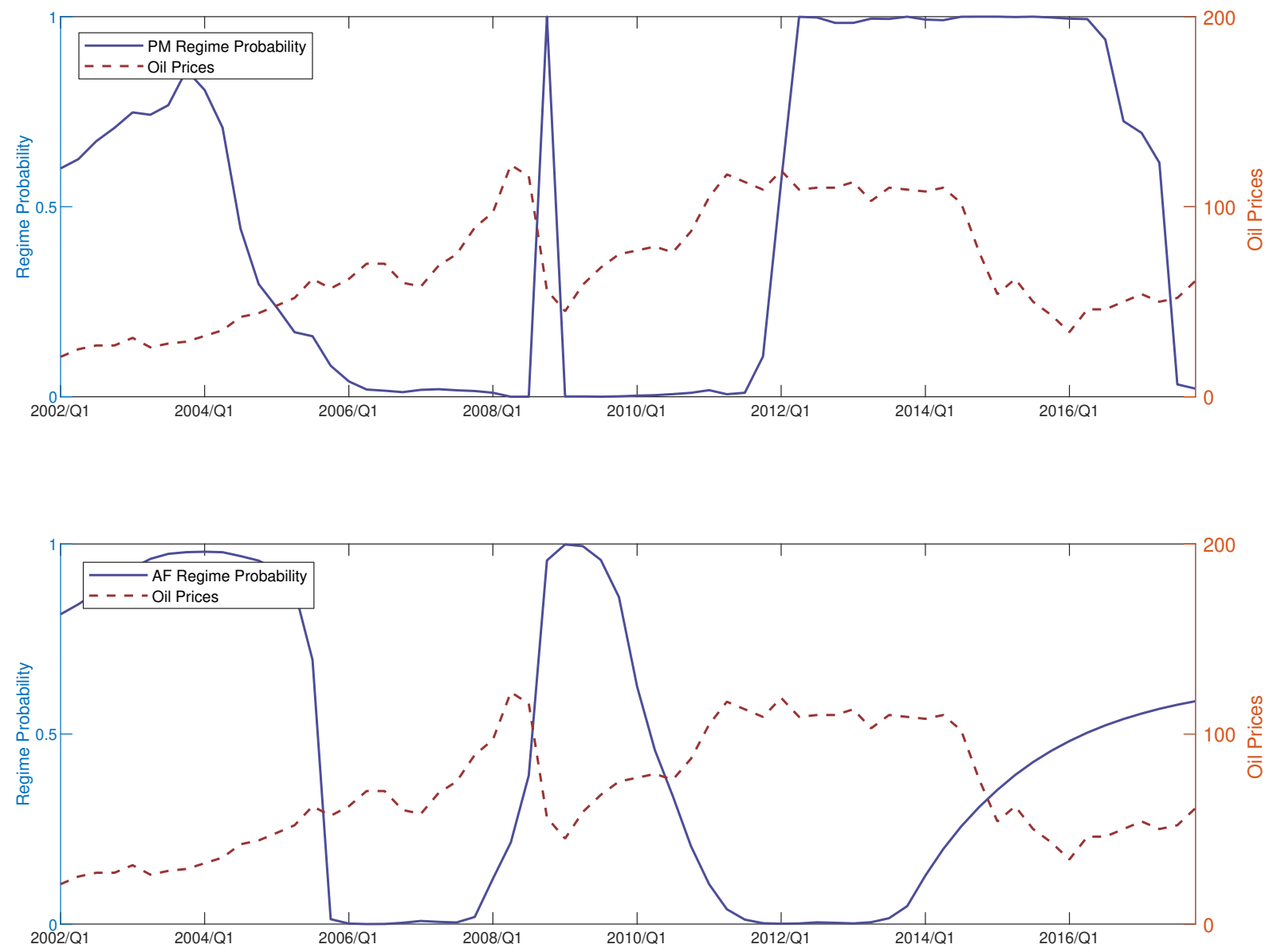

Figure 9: Smoothed State Probabilities and Oil Price: The Case of Algeria 